University of Nebraska - Lincoln

DigitalCommons@University of Nebraska - Lincoln

$1-30-2009$

Descriptions of eight new species of Phaelota (Coleoptera:

Chrysomelidae) with a new generic synonymy and a key to species of Indian subcontinent

Kaniyarikkal Divakaran Prathapan

Alexander S. Konstantinov

Follow this and additional works at: https://digitalcommons.unl.edu/usdaarsfacpub

This Article is brought to you for free and open access by the U.S. Department of Agriculture: Agricultural Research Service, Lincoln, Nebraska at DigitalCommons@University of Nebraska - Lincoln. It has been accepted for inclusion in Publications from USDA-ARS / UNL Faculty by an authorized administrator of DigitalCommons@University of Nebraska - Lincoln. 


\title{
Descriptions of eight new species of Phaelota (Coleoptera: Chrysomelidae) with a new generic synonymy and a key to species of Indian subcontinent
}

\author{
K. D. PRATHAPAN ${ }^{1} \&$ A. S. KONSTANTINOV ${ }^{2}$ \\ ${ }^{\prime}$ Department of Entomology, Kerala Agricultural University, Vellayani P. O., Trivandrum - 695 522, Kerala, INDIA. \\ E-mail: prathapankd@gmail.com \\ ${ }^{2}$ Systematic Entomology Laboratory, PSI, Agricultural Research Service, U. S. Department of Agriculture, c/o National Museum of \\ Natural History, MRC 168 Washington, DC 20560, U. S. A. E-mail: akonstan@sel.barc.usda.gov
}

\begin{abstract}
Six new species of Phaelota Jacoby from India viz. P. assamensis, P. kottigehara, P. maculipennis, P. mauliki, P. saluki, and $P$. viridipennis and two new species from Sri Lanka viz. P. ogloblini and P. schereri are described and illustrated. Thrylaea Jacoby is treated as a new junior synonym of Phaelota. A lectotype for Phaelota variabilis (Jacoby) is designated and the species is removed from the synonyms of P. flavipennis (Motschulsky). The consequences of loss of flight on host plant selection in Phaelota are discussed and a key to the species of the Indian subcontinent is provided.
\end{abstract}

Key words: Chrysomelidae, Phaelota, Thrylaea, new synonym, new species, Indian subcontinent, apterism, host plant selection

\section{Introduction}

Phaelota, a flea beetle genus described by Jacoby (1887) from Sri Lanka, was recently revised with descriptions of three new species from south India (Prathapan and Viraktamath, 2004). Six new species of Phaelota from India and two new species from Sri Lanka are described here, a new generic synonymy is recognized and a key to the species of Phaelota of the Indian subcontinent is provided. Species of this genus were reported to feed on ferns (Prathapan and Viraktamath, 2004). Most of the material studied here was collected by the authors in southern India and this provides new insights into the trophic selections of the genus with respect to the ability to fly. With this contribution, the number of known species of Phaelota has become 16, including P. unicolor (Chen) from the Philippines and P. kerzhneri Prathapan and Konstantinov from Borneo.

The descriptive terminology follows Konstantinov (1998). The holotypes are deposited in the National Museum of Natural History, Smithsonian Institution, Washington, DC (USNM). Other specimens used in this study are deposited in the following collections: National Pusa Collection, Indian Agricultural Research Institute, New Delhi (NPC), Natural History Museum, London (BMNH), Natural History Museum, Basel, Switzerland (NHMB), University of Agricultural Sciences, Bangalore (UASB), and the personal collection of the first author (PKDC).

\section{Genus Phaelota Jacoby}

Phaelota Jacoby, 1887: 94 (Type species: Phaelota semifasciata Jacoby, 1887, Sri Lanka, by monotypy); Maulik, 1926: 176; Chen, 1936: 659; Heikertinger and Csiki, 1940: 511; Scherer, 1969: 8, 18, 218; Seeno and Wilcox, 1982: 144; Prathapan and Viraktamath, 2004: 1-18. 
Thrylaea Jacoby, 1887: 98 (Type species: Thrylaea variabilis Jacoby, 1887, Sri Lanka, by monotypy); Maulik, 1926: 284, 307; Chen, 1936: 659; Heikertinger and Csiki, 1940: 528; Scherer, 1969: 7, 233; Seeno and Wilcox, 1982 : 144. New synonym.

Distribution. India, Sri Lanka, the Philippines and Borneo.

Diagnostic characters. Alate or apterous, 1.9 to $5.2 \mathrm{~mm}$ long, convex, ovoid, narrowed posteriorly. Antennal callus well developed, transverse to oblique, anteromesal end triangular and entering into interantennal space. Distance between eye and adjacent antennal socket subequal to transverse diameter of a socket or slightly less; distance between antennal sockets $1.5-4.7$ times diameter of a socket and less than transverse diameter of one eye. Frontal ridge wide, widening anteriorly. Anterofrontal ridge lower than frontal ridge, flat. Labrum with a transverse row of four setiferous punctures. First antennomere as long as next two combined, last five or six antennomeres thickened. Pronotum transverse, $1.3-1.8$ times wider than long, with poorly developed antebasal transverse impression delimited on either end by curved longitudinal impressions. Procoxal cavity closed behind. Prosternum broad. Elytra as wide as prothorax at base, widening at humerus. Elytral punctures arranged in striae. Epipleuron moderately wide, reaching beyond $4 / 5^{\text {th }}$ of elytron. Dorsal surface of metatibia more or less flat. Metabasitarsus slightly longer than next two tarsomeres combined. In repose, metatibia received over a longitudinal ridge along mesal side of metafemur, edge of this ridge being distinctly serrulate in male.

Remarks. Though described in the same paper, Jacoby (1887) did not compare Phaelota with Thrylaea as in the case of Ivalia and Amphimeloides (Duckett et al., 2006). A syntype of Thrylaea variabilis Jacoby was examined and found to be a typical alate Phaelota with all the salient features of the genus including the serrulate metafemur in the male. No significant character separates it from P. semifasciata Jacoby or other congenerics. Hence Thrylaea is synonymised with Phaelota and as both the names were published in the same paper, we here give precedence to Phaelota.

\section{Phaelota assamensis, new species}

(Figs 1-6)

\section{Distribution. India (Assam).}

Host plants. Unknown.

Description. Total body length $3.2 \mathrm{~mm}$, width $2.1 \mathrm{~mm}$. Each elytron with three black patches at humeral callus, below scutellum and at apex (Figs 1, 5). Pronotum blackish except for anterior and lateral margins being light brown. Head with vertex dark brown and facial part light brown. Six basal antennomeres light brown, rest black. Legs dark brown, except for tibial apex light brown.

In lateral view, vertex and frons form convex line, their intersection being concave and proximal end of frons higher than vertex. Vertex punctate (Fig. 2). Antennal callus slightly raised, oblique, shorter than wide, low near supracallinal sulcus, high near supraantennal sulcus, separated from each other by midfrontal depression. Suprafrontal sulcus well developed, midfrontal sulcus poorly developed. Frontal ridge slightly wrinkled. Anterofrontal ridge without vertical carina medially. Maxillary palpus with preapical palpomere subequal to half of apical palpomere. Third antennomere nearly as long as second (Fig. 2). Tenth antennomere nearly as wide as long.

Lateral margin of pronotum nearly straight (Fig. 3), anterolateral callosity forms obtuse denticle at pore. Disc shiny, punctation fine, stronger than that on vertex. Antebasal transverse impression absent except for imperceptible curved longitudinal line laterally on each side near posterior margin. Scutellum shiny, impunctate, triangular, wider than long, apex narrowly rounded. Elytron with well developed humeral callus (Figs 1, 5 ), with very slight depression posteriorly, maximum width at proximal $1 / 3$. Striae slightly depressed. Interstices flat with extremely minute punctures. Width of interstices subequal to 4-7 times diameter of a puncture. 
Epipleuron oblique, not reaching apex. Metasternum about two times as long as prosternum. Metafemur with flat ridge along its posterior edge (Fig. 4). Metatibia straight in lateral view, curved from dorsal view, proximal $1 / 3$ dorsally convex, rest of surface nearly flat. Claw longer than metatibial spine.

Median lobe of aedeagus slightly constricted in middle (Fig. 6), widening apically, with obtuse denticle at apex. Apical one third slightly flattened on ventral side.
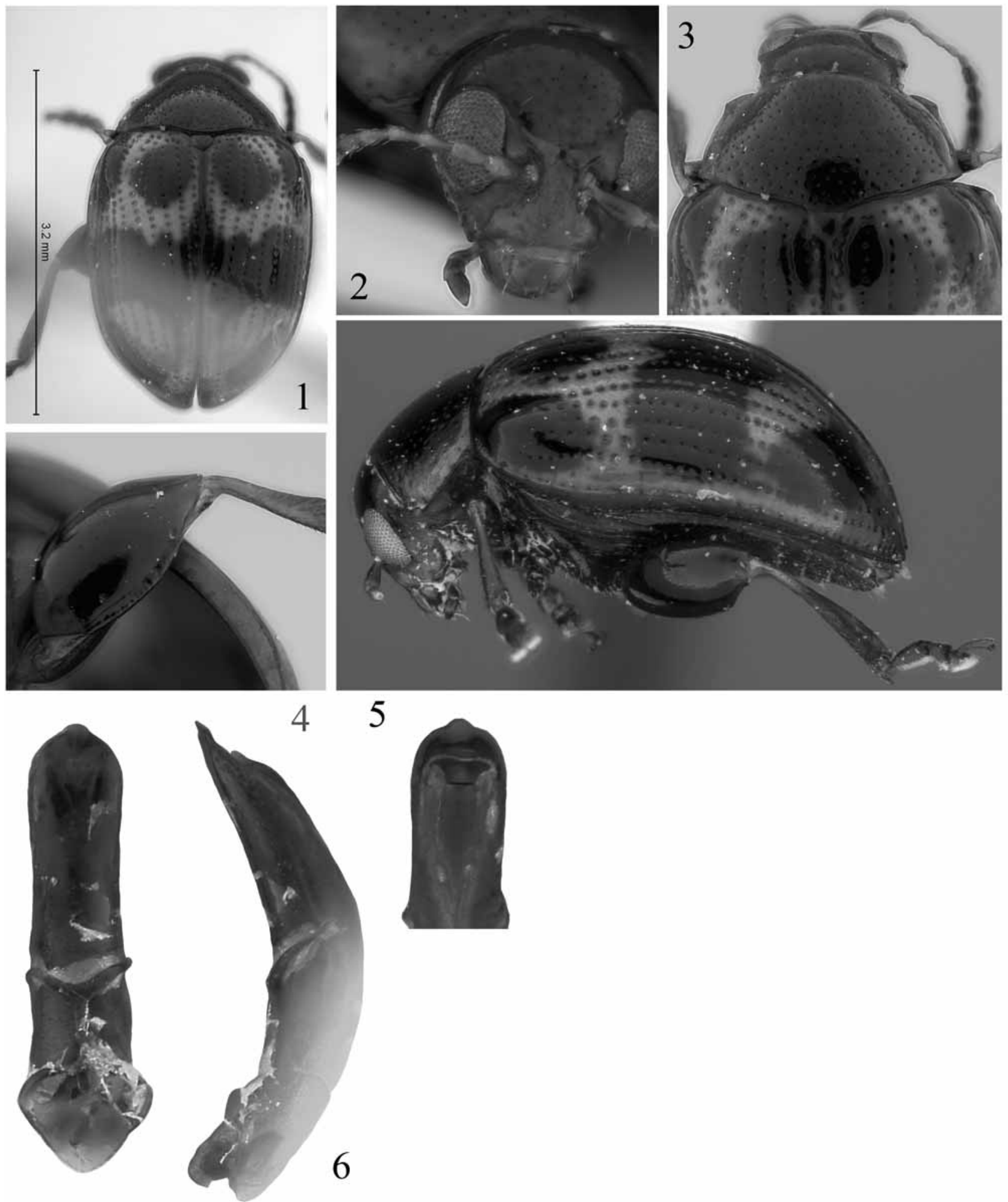

FIGURES 1-6. Phaelota assamensis. 1 - dorsal habitus, 2 - head, 3 - pronotum, 4 - metafemur, 5 - lateral habitus, 6 median lobe of aedeagus in ventral, lateral, and dorsal views. 
Female unknown.

Type material. Holotype $\widehat{~}$. Labels: 1) Doom Dooma, Assam, May 29 1943, DE Hardy; 2) Holotype Phaelota assamensis sp. nov. des. D. Prathapan, A. Konstantinov, 2007 (USNM).

Etymology. The specific epithet is an adjective based on the type locality.

Remarks. Phaelota assamensis can be separated from all other species of Phaelota based on the elytra with dark spots and bands and the dark pronotum with anterior and lateral margins light brown.

\section{Phaelota flavipennis (Motschulsky) New combination}

(Figs 7-12)

Hypnophila flavipennis Motschulsky, 1866: 39 (Sri Lanka, lectotype, designated by Medvedev, 2006, not examined); Scherer, 1969: 233.

Kamala flavipennis: Maulik, 1926: 259; Scherer, 1969: 234.

Thrylaea flavipennis: Ogloblin, 1930: 98; Heikertinger and Csiki, 1940: 528; Scherer, 1969: 234.

Distribution. Sri Lanka.

Host plants. Unknown.

Description. Total body length $3.0 \mathrm{~mm}$, width $2.1 \mathrm{~mm}$. Body entirely light brown, with pronotum and tibial apex darker. Last 5 antennomeres dark brown (Fig. 7).

In lateral view, vertex and frons form convex line, their intersection being concave and proximal end of frons higher than vertex. Vertex minutely punctate (Fig. 10). Antennal callus slightly raised, oblique, shorter than wide, as low near supracallinal sulcus as near supraantennal sulcus, separated from each other by round midfrontal impression. Suprafrontal sulcus poorly developed medially, absent laterally, midfrontal sulcus poorly developed. Frontal ridge smooth. Anterofrontal ridge without vertical carina medially. Maxillary palpus with preapical palpomere subequal to more than half of apical palpomere. Third antennomere nearly as long as second (Fig. 11). Tenth antennomere longer than wide.

Lateral margin of pronotum slightly convex (Fig. 8), anterolateral callosity forms acute denticle at pore. Disc shiny, punctation fine, much stronger than that on vertex. Antebasal transverse impression absent except for small curved longitudinal line laterally on each side near posterior margin. Scutellum shiny, impunctate, triangular, wider than long, apex rounded. Elytron with well developed humeral callus (Fig. 7), without depression posteriorly, maximum width at proximal 1/3. Striae slightly depressed. Interstices flat with small punctures. Width of interstices subequal to 4-7 times diameter of a puncture. Epipleuron oblique, not reaching apex. Metasternum about two times as long as prosternum. Metafemur with flat, serrated ridge along its posterior edge (Fig. 9). Metatibia straight in lateral view, curved from dorsal view, proximal 1/3 dorsally convex, rest of surface nearly flat. Claw longer than metatibial spine.

Median lobe of aedeagus gently curved in lateral view (Fig. 12), with apex bent dorsally in lateral view. Ventral side convex, slightly narrowed in basal one third, apex gently depressed, with a pair of longitudinal depressions ending gradually towards base, with ridge narrowing towards apex; dorsal opening partially covered by lamina sclerotized along middle (Fig. 12).

Female unknown.

Material examined. Õ. Labels: 1) Ceylon: Kan, Dist., Udawattakelle, 25-30 Oct. 1966, J.F.G. Clarke Thelma M. Clarke; 2) Phaelota flavipennis (Motschulsky) det. Prathapan and Konstantinov, 2008 (USNM).

Remarks. Although Medvedev (2006) recently designated the lectotype of this species, it remains inaccessible for our study. We based our concept of this species on the specimen that we identified as P. flavipennis with the help of the detailed illustration of the median lobe of the aedeagus provided by Ogloblin (1930). In the key, P. flavipennis is in the same couplet with P. variabilis from which it can be easily separated based on its larger size (P. flavipennis is $3.0 \mathrm{~mm}$ long, $P$. variabilis is $2.3 \mathrm{~mm}$ ), pronotum darker than the elytra (in $P$. 

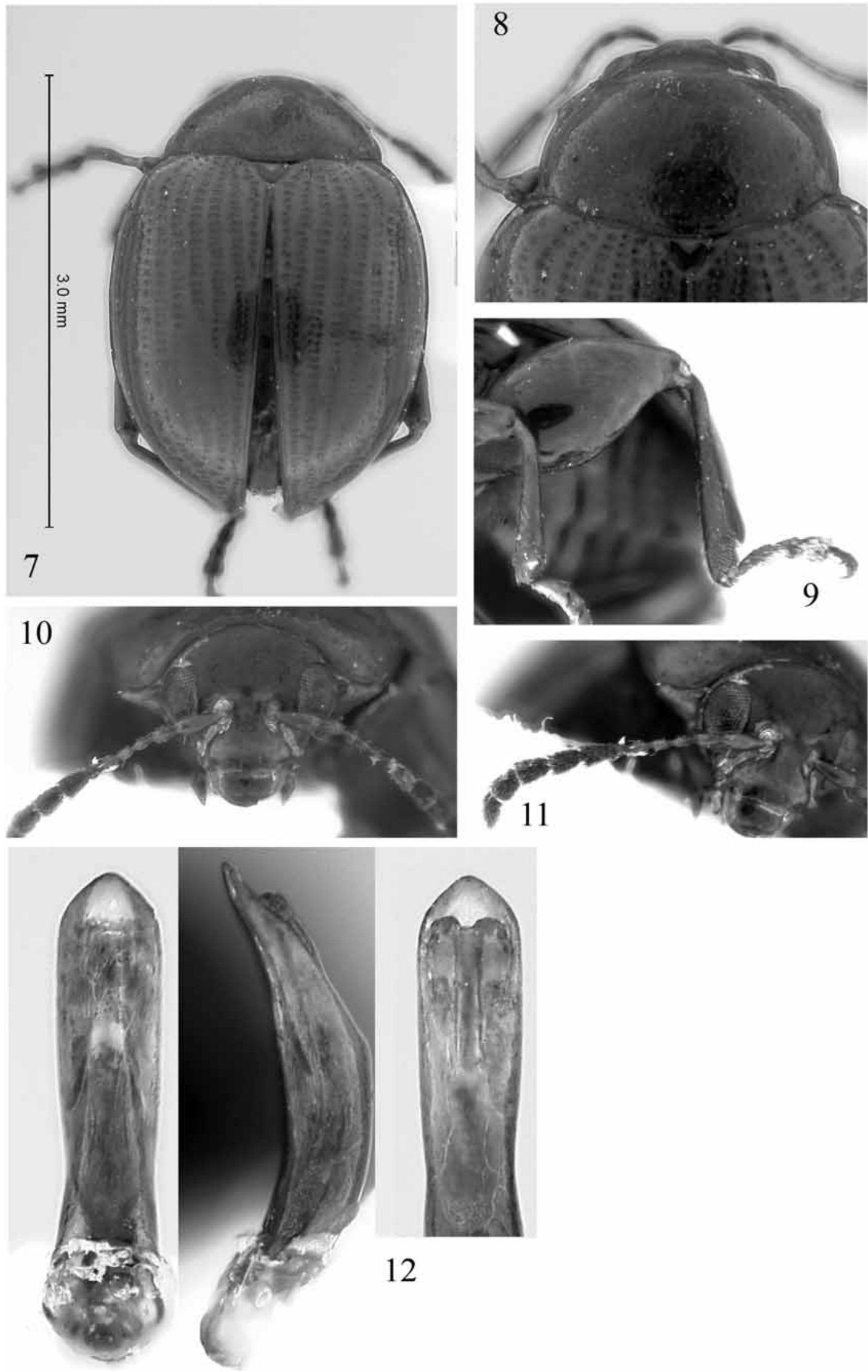

FIGURES 7-12. Phaelota flavipennis. 7 - dorsal habitus, 8 - pronotum, 9 - metafemur, 10 - head, 11 - antenna, 12 median lobe of aedeagus in ventral, lateral, and dorsal views. 
variabilis, pronotum is of lighter color than elytra) and the median lobe of the aedeagus with the apex bent dorsally in lateral view (in P. variabilis apex bent ventrally, Fig. 74).

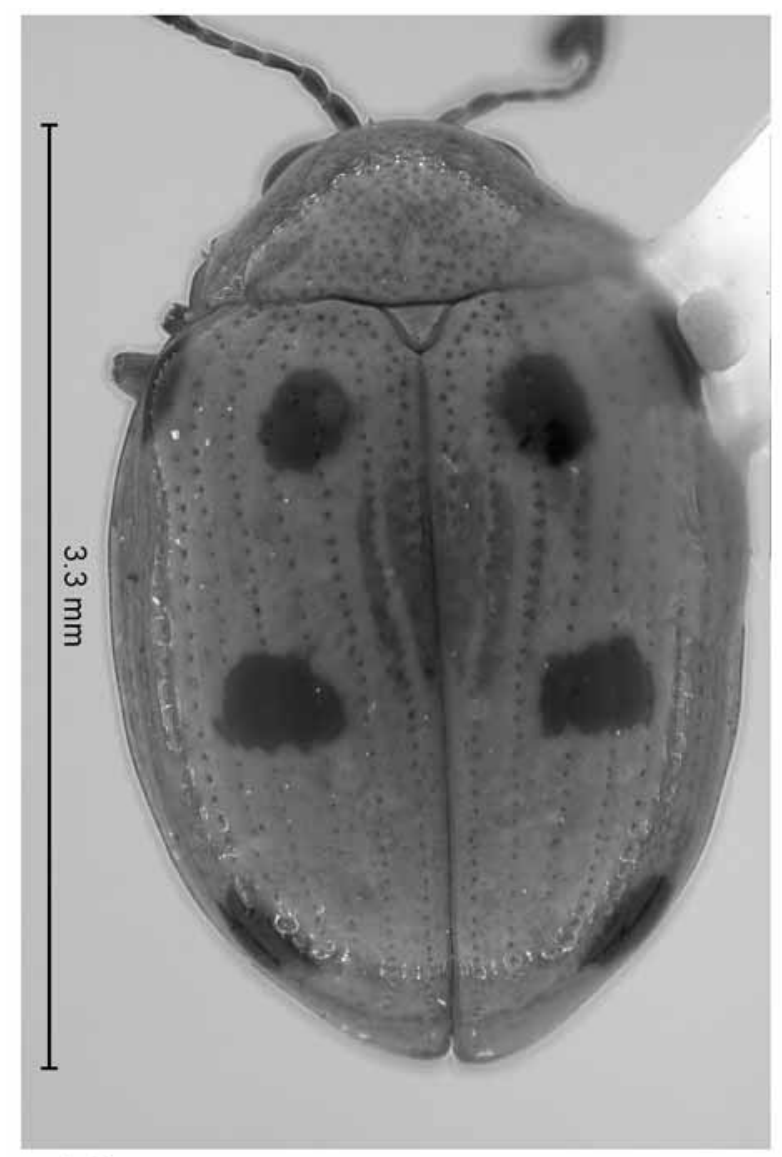

13

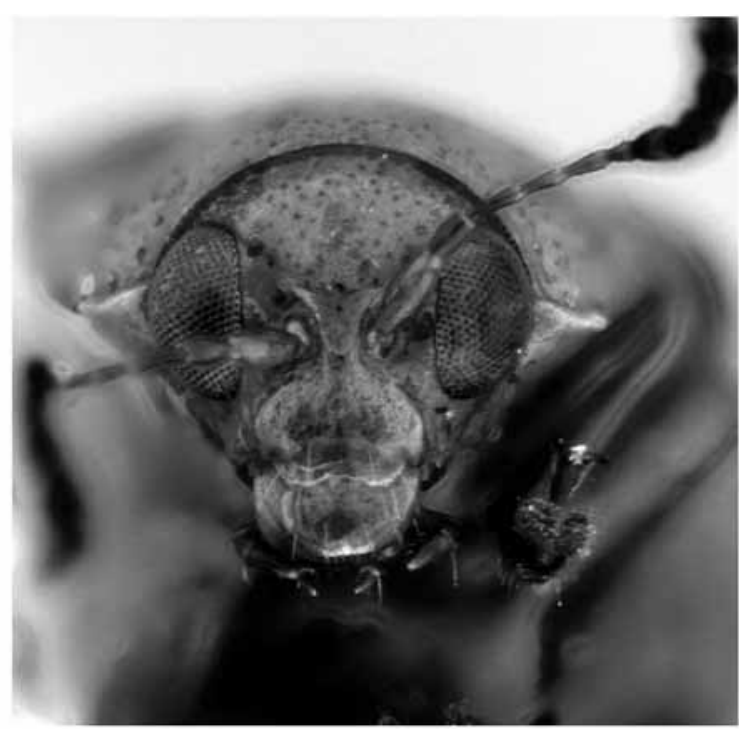

14

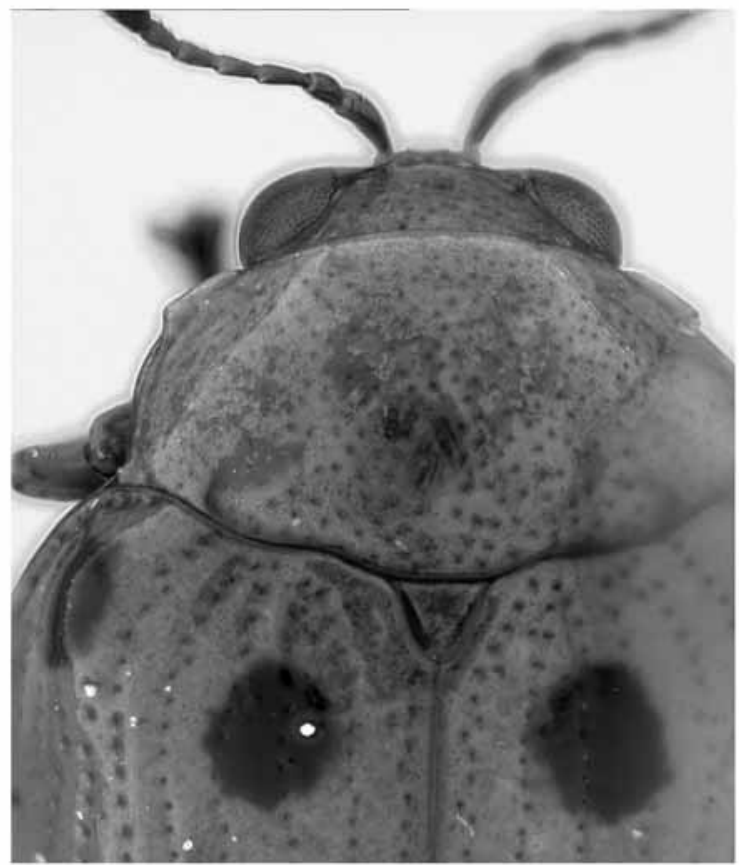

15

FIGURES 13-15. Phaelota jacobyi. 13 - dorsal habitus, 14 - head, 15 - pronotum.

\section{Phaelota kottigehara, new species}

(Figs 16-21)

Distribution. India (Karnataka).

Host plants. Collected on unidentified fern.

Description. Total body length $3.8 \mathrm{~mm}$, width $2.5 \mathrm{~mm}$. General color shining chocolate brown. Each elytron with three black patches: anterior patch confined between humeral callus and first mesal row of punctures and narrowly extending backwards near suture reaching up to $1 / 3$ of elytron; lateral patch indistinct, on 
lateral side of humeral callus; posterior patch smaller than anterior patch, irregular, placed slightly behind middle (Fig. 16). Antenna black except basal two antennomeres and apex of last antennomere brown. All tarsi and tibiae piceous except tibiae brown proximally. Apex of metafemora dark brown.

In lateral view, vertex and frons form convex line, their intersection being concave and proximal end of frons higher than vertex. Vertex finely punctate, moderately convex (Fig. 18). Antennal callus slightly raised, oblique, longer than wide, low near supracallinal sulcus, high near supraantennal sulcus, separated from each other by midfrontal depression extending into interantennal space. Suprafrontal and midfrontal sulci poorly developed. Frontal ridge sparsely punctate. Anterofrontal ridge without vertical carina medially. Maxillary palpus with preapical palpomere subequal to half of apical palpomere. Third antennomere distinctly longer than second; fourth apparently shorter than third; fourth to sixth subequal in length; seventh longer than sixth; eighth to tenth subequal, apparently shorter than seventh; eleventh slightly shorter than two times length of tenth. Width of tenth antennomere more than half of its length.

Pronotum anteriorly narrower than posteriorly (Fig. 17). Lateral margin weakly curved, anterolateral callosity forms blunt obtuse denticle at pore. Disc shiny, punctation fine, yet stronger than those on vertex, with a few stronger punctures near middle of posterior margin. Antebasal transverse impression absent except for imperceptible curved vertical line laterally on each side near posterior margin. Scutellum shining, impunctate, triangular, wider than long, apex narrowly rounded. Elytron with well developed humeral callus, with depression posteriorly, maximum width at proximal $1 / 3$. Interstices flat with extremely minute punctures. Width of interstices subequal to 4-7 times diameter of a puncture. Epipleuron oblique, not reaching apex. Metasternum about two times as long as prosternum. Metatibia straight in lateral view, curved from dorsal view, proximal 1/ 3 dorsally convex, rest of surface nearly flat. Claw longer than metatibial spine.

Receptacle of spermatheca shorter than pump (Fig. 19). Internal side of receptacle strongly convex, external side weakly convex. Pump strongly curved like a hook. Vaginal palpus sclerotised along medial margin; of uniform width in distal half; proximal sclerotization lighter than distal sclerotization, each subequal to unsclerotized area in middle (Fig. 20). Tignum slightly curved proximally, distal sclerotized part slightly widened (Fig. 21).

Male unknown.

Type material. Holotype +. Labels: 1) India Karnataka Kottigehara 22.IX.2004 Prathapan Coll. 2) Holotype Phaelota kottigehara sp. nov. des. D. Prathapan, A. Konstantinov, 2007 (USNM).

Etymology. The specific epithet is a noun in apposition based on the type locality.

Remarks. Phaelota kottigehara can be separated from P. jacobyi Prathapan and Viraktamath by its excarinate anterofrontal ridge (anterofrontal ridge with a vertical carina medially in $P$. jacobyi) and extremely short spermathecal duct (spermathecal duct nearly twice as long as receptacle in P. jacobyi). The antebasal transverse impression is laterally well impressed and strongly punctate in $P$. jacobyi while it is imperceptible in $P$. kottigehara. The general color as well as elytral spots are also different in these two species. $P$. sindhoori Prathapan and Viraktamath resembles $P$. kottigehara in having a short spermathecal duct, but they can be easily separated by the chocolate brown color and black spots on the elytron in P. kottigehara ( $P$. sindhoori is entirely brownish red except eyes and 5-7 distal antennomeres piceous, Figs 59-62). The receptacle of the spermatheca in $P$. sindhoori is subequal to the pump with a concave outer side (receptacle shorter than pump with either sides convex in P. kottigehara). P. vaishakha Prathapan and Viraktamath can be easily separated from P. kottigehara by the following characters: transverse, highly convex antennal callus (Figs 64-69) (antennal callus oblique, longer than wide and moderately convex in P. kottigehara); antebasal transverse impression distinct (antebasal transverse impression nearly imperceptible in P. kottigehara) and lateral pronotal margin strongly curved (lateral pronotal margin weakly curved in P. kottigehara). P. flavipennis can be separated from $P$. kottigehara by transverse antennal callus and distinct antebasal transverse impression. $P$. kottigehara is similar to P. mauliki n. sp. but can be separated by its excarinate anterofrontal ridge (anterofrontal ridge is with a vertical carina medially in P. mauliki) and the shape of the spermatheca which has a con- 
vex outer side (outer side of spermatheca concave in $P$. mauliki). Though the color is highly variable in $P$. mauliki, it lacks black spots on elytron (P. kottigehara has black spots on the elytron).

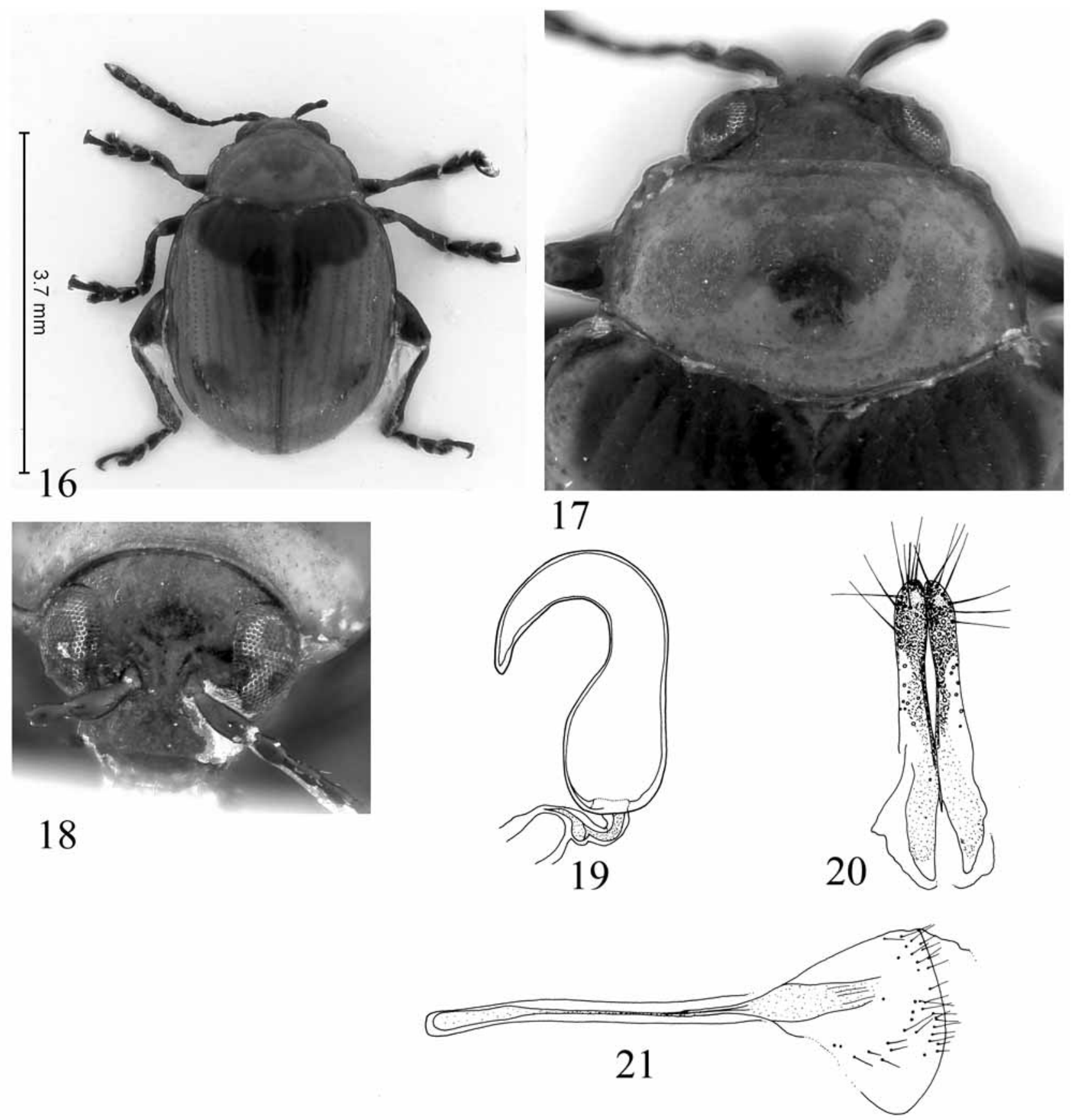

FIGURES 16-21. Phaelota kottigehara. 16 - dorsal habitus, 17 - pronotum, 18 - head, 19 - spermatheca, 20 - vaginal palpi, 21 - tignum.

\section{Phaelota maculipennis, new species}

(Figs 22-30)

Distribution. India (Tamil Nadu).

Host plants. Collected by sifting moss.

Description. Total body length $2.4 \mathrm{~mm}$, width $1.6 \mathrm{~mm}$. Head, pronotum black. Elytron all around and suture piceous enclosing light yellowish area in middle. Dark color of the margin spreads to light colored area 
in middle forming variously shaped macula varying greatly among individuals (Figs 22, 26). Frontal region and mouth parts brown. Basal 5-6 antennomeres brown, rest piceous. All legs and ventrites brown.

In lateral view, frons and vertex each forming distinctly convex lines and their intersection appears notched; frons as high as vertex. Vertex convex, extremely finely punctate (Fig. 23). Antennal callus raised, triangular with acute lateral end, broader than long, high along middle. Antennal calli separated by a short midfrontal depression not entering into interantennal space. Midfrontal and suprafrontal sulci indistinct. Frontal ridge distinctly convex, extremely minutely punctate. Anterofronal ridge without vertical carina medially. Maxillary palpus with preapical palpomere slightly longer than half of apical. Second and third antennomeres subequal in length; fourth shorter than third; fourth to sixth subequal in length, sixth slightly thicker than fifth; seventh onwards antennomeres distinctly thickened; seventh to ninth each subequal, longer than sixth; tenth subequal to ninth or longer, longer than wide; eleventh about two times as long as tenth.

Pronotum slightly narrower anteriorly than posteriorly (Fig. 24). Lateral margin weakly curved. Anterolateral callosity forming obtuse denticle at pore. Disc shiny, uniformly covered with small punctures. Antebasal transverse impression imperceptible except for a few bold punctures near posterior margin. Scutellum two times broader than long, semicircular, impunctate. Elytron with humerus flat, without depression posteriorly or mesally, maximum width anterior to middle. Surface shiny, punctures bold, deep, distinct posteriorly. Interstices flat with a mixture of small and moderate sized punctures; width of interstices 3-6 times diameter of a puncture in middle of elytron. Epipleuron subhorizontal, slightly short of reaching apex. Metasternum slightly shorter than prosternum. Metatibia nearly straight in lateral view, curved from dorsal view. Dorsal surface flat in distal half, rest of it convex. Metatibial spine longer than tarsal claw.

Posterior margin of last abdominal sternite in male neither distinctly bisinuate nor with a distinct lobe in middle. Median lobe of aedeagus strongly curved in lateral view with acute apex (Fig. 25). Ventral side with a longitudinal furrow extending from proximal end not reaching apex; apex nearly flat. Dorsal opening with three laminae, middle one distinctly sclerotised, laminae not covering opening. Arm of tegmen shorter than stem (Fig. 28); spicule Y-shaped.

Receptacle of spermatheca longer than pump, internal and external sides convex, oblong; length slightly shorter than two times width; maximum width below middle. Pump shorter than receptacle, with vertical part shorter than horizontal. Duct a little shorter than two times length of receptacle (Fig. 27). Proximal half of vaginal palpus much wider than distal half, maximum width at distal 1/3; distal sclerotization darker than proximal sclerotization, both being undifferentiated and subequal. Lateral membranous area in middle longer than half of vaginal palpus (Fig. 29). Tignum straight, proximally wider than sclerotized part of apex (Fig. 30).

Sexual dimorphism. Ventral side of first pro- and mesotarsomeres in female with pointed setae. In male, setae on the ventral side of first pro- and mesotarsomeres are short and plumose-capitate. Metafemur is sexually dimorphic as in other species of the genus.

Type material. Holotype $\widehat{\jmath}$. Labels: 1) SOUTH INDIA Western Ghats Tamil Nadu, $35 \mathrm{~km}$ SW Kodaikanal 30.XI.2003, 2060 m Kukal Shola N10 16' 23" E 77²1' 55", leg. Konstantinov, Prathapan, Saluk; 2) Holotype Phaelota maculipennis sp. nov. des. D. Prathapan, A. Konstantinov, 2007 (USNM). Paratypes 1 ऽ, 1 the same labels as holotype (USNM, PKDC).

Etymology. The species name refers to the maculate elytron and is an adjective.

Remarks. Phaelota maculipennis can be differentiated from most other flightless species of Phaelota by its black head and pronotum (head and pronotum yellow to dark brown in other species) and the characteristic color pattern of the elytron. The dorsum is entirely metallic black in P. saluki $\mathbf{n}$. sp. and elytron is metallic black with greenish reflections and the pronotum is brown in $P$. viridipennis $\mathbf{n}$. sp., the other two flightless species known from the hills of the Western Ghats. A unique character of P. maculipennis is the Y-shaped spicule. The aedeagus with a deep furrow along the ventral side is another diagnostic feature. $P$. 

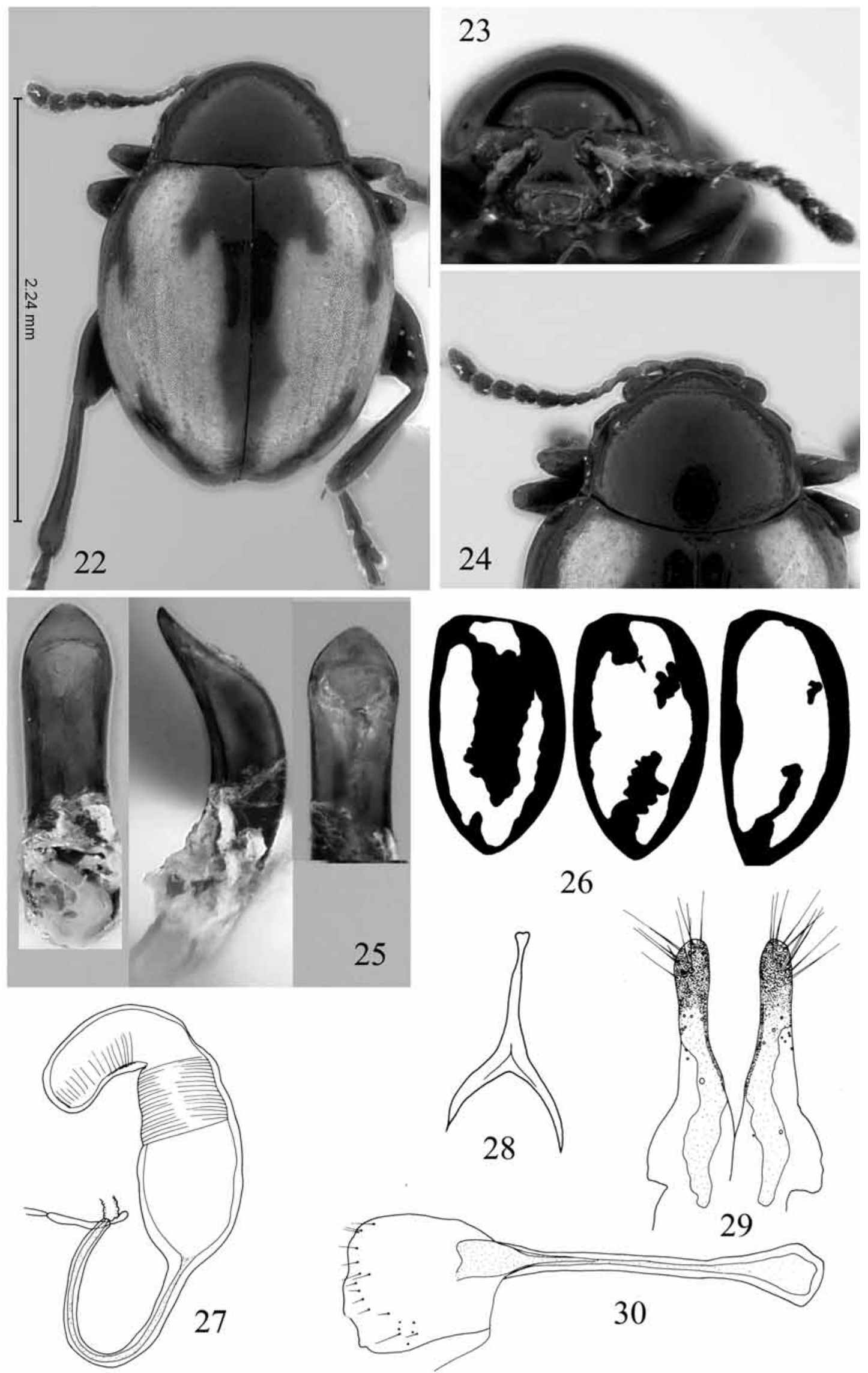

FIGURES 22-30. Phaelota maculipennis. 22 - dorsal habitus, 23 - head, 24 - pronotum, 25 - median lobe of aedeagus in ventral, lateral, and dorsal views, 26 - elytral pattern, 27 - spermatheca, 28 - tegmen, 29 - vaginal palpi, 30 - tignum. 
maculipennis and $P$. viridipennis share several features like the highly raised antennal callus, convex vertex and posterior margin of the last abdominal sternite in male without a distinct lobe in middle.

\section{Phaelota mauliki, new species}

(Figs 31-39)

\section{Distribution. India (Tamil Nadu).}

Host plants. Collected on unidentified ferns.

Description. Total body length $2.7-4.2 \mathrm{~mm}$, width $1.9-2.7 \mathrm{~mm}$. Color highly variable. Two distinct color morphs - yellow or red and black- and their intermediates were observed (Figs 31-33). Red and black form: head, pronotum, legs, antennae, thoracic sternites piceous to black; elytron, abdominal sternites red except first abdominal sternite being red to piceous; labrum, apex of basal five antennomeres, anterofrontal ridge, mouth parts, antennal socket, base of first antennomere, trochanter, claw tarsomere lighter than head and thorax. Yellow form: entirely shining light yellow, except six distal antennomeres black; all tarsomeres dark brown; apex of all tibiae, basal five antennomeres darker than rest of body; apex of last antennomere brown. Dorsum of one specimen entirely shining black except brown apices of basal five antennomeres.

Frons and vertex form slightly convex line in lateral view. Vertex shining, moderately convex, finely punctate. Antennal callus oblique, about as wide as long, raised near margin with antennal socket than posterior or mesal margins. Antennal calli slightly raised, separated from each other by midfrontal sulcus that continue into interantennal space as shallow midfrontal longitudinal depression. Suprafrontal sulcus poorly developed. Frontal ridge shiny, extremely minutely punctate. Anterofrontal ridge sharply carinate medially. Maxillary palpus with apical palpomere about two times as long as preapical. Third antennomere distinctly longer than second; 3-5 each subequal in length, fifth being slightly wider than third and fourth; sixth subequal to or longer than fifth; seventh longer, wider than sixth; eighth slightly shorter than seventh; ninth subequal to or slightly longer than eighth; tenth apparently longer than wide, subequal to or shorter than ninth; eleventh slightly shorter than two times length of tenth.

Pronotum anteriorly narrower than posteriorly, lateral margins almost straight (Fig. 31). Anterolateral callosity forming obtuse denticle at pore. Disc shiny, punctures minute to medium sized, stronger towards distal region, size of largest puncture being less than half as those on base of elytron. Antebasal transverse impression indistinct, represented by a weak, short longitudinal impression on either side, almost nonexistent in majority of specimens. Mesoscutellum shiny, extremely minutely punctate, triangular, apex narrowly rounded, slightly wider than long. Elytron with well developed humeral callus, with depression posteriorly, maximum width at anterior 1/3. Disc shiny, punctures bold, interstices flat with a mixture of minute to small punctures. Punctures turn indistinct posteriorly. Width of interstices in anterior half vary from 3-6 times diameter of a puncture. Epipleuron subhorizontal, not reaching apex. Metasternum about two times as long as prosternum. Metatibia straight in lateral view, slightly curved from dorsal view; dorsally convex in proximal 1/3, concave in distal $1 / 4$, rest of surface flat.

Posterior margin of last abdominal sternite in male weakly bisinuate with a transverse lobe in middle (Fig. 39). Median lobe of aedeagus gently curved with weakly recurved apex in lateral view (Fig. 34); ventral side convexly raised like a ridge along middle, preapically with curved impressions on either side, parallel sided in ventral view. Dorsal opening incompletely covered by a rectangular lamina. Arm of tegmen shorter than stem (Fig. 35). Receptacle of spermatheca about as long as pump, internal side strongly convex, external side weakly concave with maximum width slightly above middle. Pump with horizontal part slightly longer than vertical. Duct shorter than receptacle (Fig. 36). Vaginal palpus with membranous part in middle longer than anterior sclerotization or posterior sclerotization; anterior sclerotization apparently longer than posterior; slightly narrowed near middle, widening proximally (Fig. 37). Tignum slightly widened anteriorly, straight in ventral view, curved in lateral view, sclerotized part of apex slightly widened (Fig. 38). 


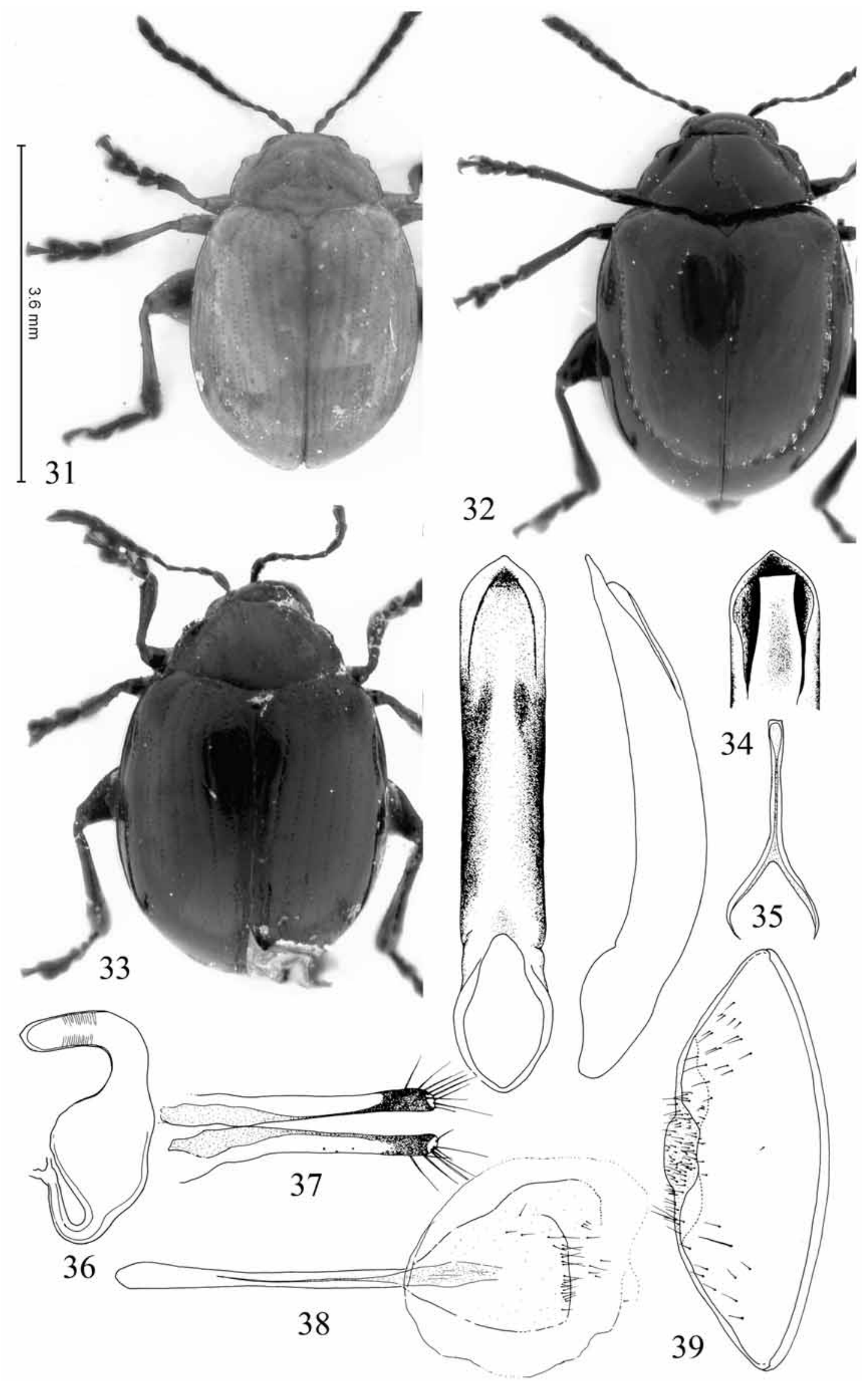

FIGURES 31-39. Phaelota mauliki. 31-33 - dorsal habiti, 34 - median lobe of aedeagus in ventral, lateral, and dorsal views, 35 - tegmen, 36 - spermatheca, 37 - vaginal palpi, 38 - tignum, 39 - last abdominal sternite of male. 
Sexual dimorphism. All first tarsomeres ventrally flat with short, capitate setae in male and with pointed setae in female. Metafemur sexually dimorphic as in other species.

Type material. Holotype $\delta^{\lambda}$. Labels: 1) SOUTH INDIA Western Ghats Tamil Nadu, Naduvattam 27.VI.2004 N11 28' 24.2" E76 33'04" Prathapan K. D. Coll. 2) Holotype Phaelota mauliki sp. nov. des. D. Prathapan, A. Konstantinov, 2007 (USNM).

Paratypes. 6 ๙, $9 q$ the same labels as holotype; 4 ภ, $3 q$ Labels: 1) SOUTH INDIA Western Ghats Tamil Nadu, Avalanche 2030m 26.VI.2004 N11 18' 00.3" E76 35'42.8" Prathapan K. D. Coll.; 2) Paratype Phaelota mauliki sp. nov. des. D. Prathapan, A. Konstantinov, 2007 (8 USNM, 4 BMNH, 2 NHMB, 2 NPC, 2 UASB, 4 PKDC).

Etymology. This species is named after Samarendra Maulik who did the first monograph on the leaf beetles of the Indian subcontinent. The name is a noun.

Remarks. Phaelota flavipennis is similar to P. mauliki in having various color forms. P. flavipennis can be differentiated from $P$. mauliki by its excarinate anterofrontal ridge and laterally well impressed antebasal transverse impression on the pronotum. The second and third antennomeres are subequal in $P$. flavipennis but the latter is distinctly longer in P. mauliki. P. mauliki closely resembles P. sindhoori Prathapan and Viraktamath, especially in the structure of the spermatheca, absence of antebasal transverse impression on the pronotum, and the oblique antennal calli, but can be differentiated from P. sindhoori by the longer midfrontal depression (shorter in P. sindhoori, Fig. 60), vertical carina in the middle of the anterofrontal ridge (anterofrontal ridge excarinate in $P$. sindhoori), epipleuron which is nearly horizontal (distinctly oblique in $P$. sindhoori) and antennal callus raised near antennal socket than near vertex (antennal callus higher near vertex than near antennal socket in $P$. sindhoori). The yellow form of $P$. mauliki resembles $P$. jacobyi in color but lacks black spots on the elytron which are invariably present in $P$. jacobyi (Figs 13, 15). In P. jacobyi the basal six antennomeres are translucent brown, not widened, and without short, dense setae, and the five distal antennomeres are black, distinctly widened with dense, short setae (in P. mauliki basal five antennomeres are translucent, not widened and without short, dense setae while the distal six antennomeres are black, distinctly widened with short, dense setae). The punctures on the vertex of $P$. jacobyi (Fig. 14) are much stronger than those on $P$. mauliki. The spermathecal duct in $P$. jacobyi is nearly two times as long as the receptacle where it is shorter than the receptacle in P. mauliki. P. vaishakha is rather hemispherical in appearance compared to $P$. mauliki which is comparatively longer and less convex. The following characters will differentiate $P$. vaishakha from P. mauliki: antennal calli transverse and narrowly separated from each other (oblique and distinctly separated by midfrontal depression in P. mauliki); anterofrontal ridge excarinate (anterofrontal ridge vertically carinate medially in P. mauliki); lateral pronotal margins strongly curved (nearly straight in $P$. mauliki); six basal antennomeres brown while distal five black (basal five brown and distal six black in $P$. mauliki); aedeagus distinctly widened at distal $1 / 3$ in ventral view (aedeagus parallel sided in ventral view in $P$. mauliki).

\section{Phaelota ogloblini, new species}

(Figs 40-44)

Distribution. Sri Lanka.

Host plants. Unknown.

Description. Total body length $2.8 \mathrm{~mm}$, width $1.9 \mathrm{~mm}$. Body light brown, with pronotum, head, antenna and leg black (Fig. 40).

In lateral view, vertex and frons form convex line, their intersection being concave and proximal end of frons higher than vertex. Vertex punctate (Fig. 43). Antennal callus slightly raised, oblique, shorter than wide, as low near supracallinal sulcus as near supraantennal sulcus, separated from each other by midfrontal depres- 
sion. Suprafrontal sulcus poorly developed medially, absent laterally; midfrontal sulcus poorly developed. Frontal ridge punctate. Anterofrontal ridge without vertical carina medially. Maxillary palpus with preapical palpomere 0.65 length of apical palpomere. Third antennomere nearly as long as second.
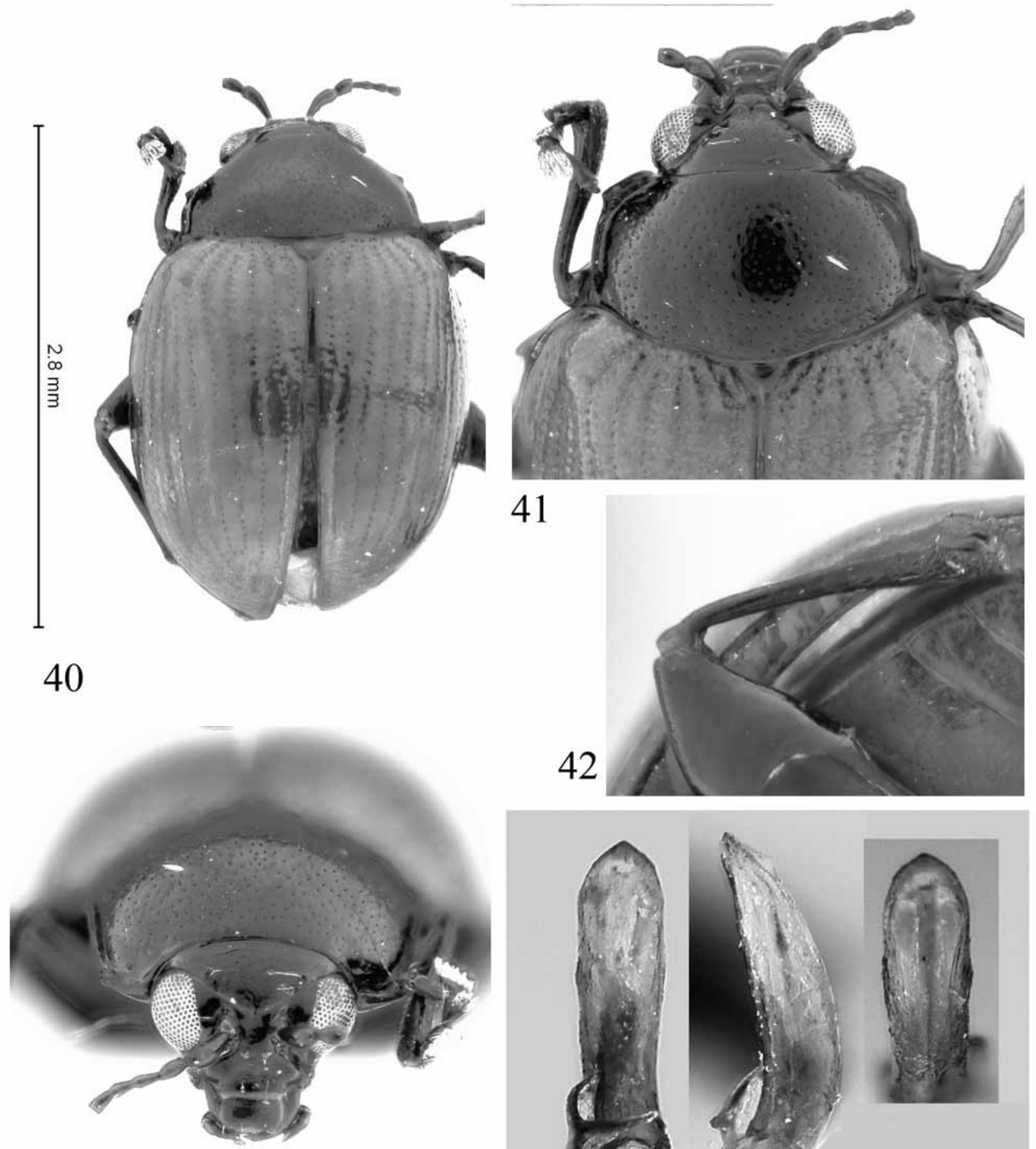

43

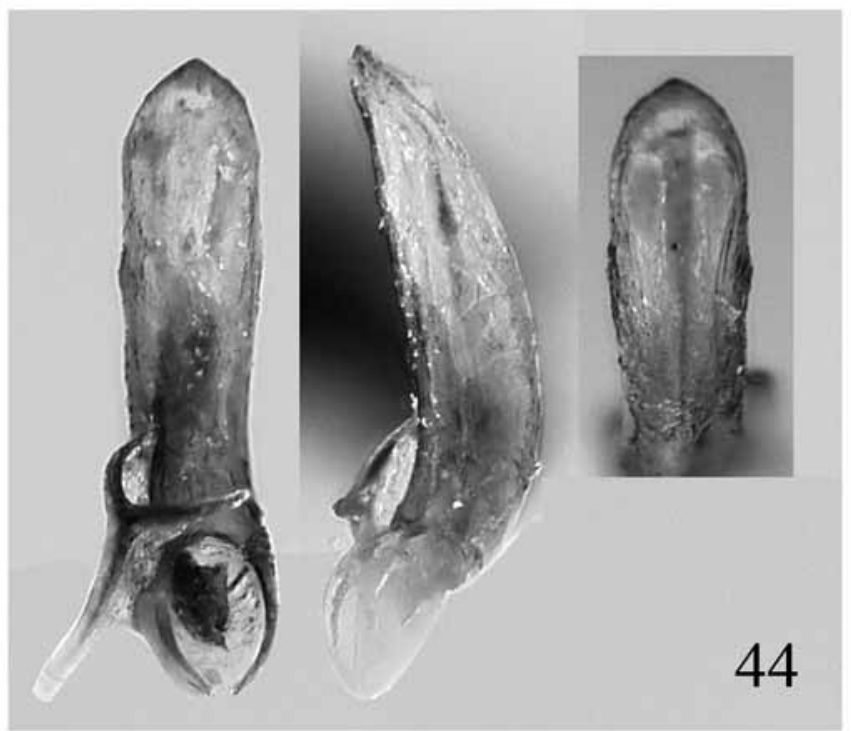

FIGURES 40-44. Phaelota ogloblini. 40 - dorsal habitus, 41 - pronotum, 42 - metafemur, 43 - head, 44 - median lobe of aedeagus in ventral, lateral, and dorsal views. 
Lateral margin of pronotum slightly convex (Fig. 41), anterolateral callosity forms acute denticle at pore. Disc shiny, punctation coarse, much stronger than that on vertex and as coarse as that of elytron. Antebasal transverse impression absent except for small barely perceptible longitudinal line laterally on each side near posterior margin. Scutellum shiny, impunctate, triangular, wider than long, apex rounded. Elytron with well developed humeral callus (Fig. 41), without depression posteriorly, maximum width at proximal 1/3. Striae depressed. Interstices flat with punctures nearly as large as those of striae. Width of interstices subequal to 4-7 times diameter of a puncture. Epipleuron oblique, not reaching apex. Metasternum about two times as long as prosternum. Metafemur with sharp denticle on posterior edge (Fig. 42). Metatibia straight in lateral view, curved from dorsal view, proximal $1 / 3$ dorsally convex, rest of surface nearly flat. Claw longer than metatibial spine.

Median lobe of aedeagus gently curved in lateral view (Fig. 44). Ventral side convex, slightly narrowed in basal one third, apex gently depressed, with a pair of longitudinal depressions ending gradually towards base, with low ridge in between; dorsal opening partially covered by lamina sclerotized along middle (Fig. 44).

Female unknown.

Type material. Holotype, ठ̊. Labels: 1) Ceylon, W. Prov. Labugama, 24 mls. ESE Colombo, 9.III.62, leg . A. Perera Loc. 17; 2) Phaelota ogloblini sp. nov. des. Prathapan and Konstantinov, 2008 (USNM).

Etymology. This species is named after Dmitry Ogloblin for his contribution to the study of leaf beetles. The name is a noun.

Remarks. In the key, P. ogloblini is in the same couplet with P. schereri from which it can be easily separated by the metafemur with a sharp denticle on its posterior edge (in P. schereri the denticle is obtuse), pronotum darker than the elytra (in P. schereri, lighter than elytra) and the median lobe of the aedeagus being straight in ventral view (in P. schereri it is slightly constricted just before the apex, Fig. 57).

\section{Phaelota saluki, new species}

(Figs 45-53)

Distribution. India (Tamil Nadu).

Host plants. Collected by sifting the moss Forsstroemia thomsonii (Mitt.) W.R. Buck (Synonym F. inclusa Cardot and Dixon), Family: Leucodontaceae (Accession No. CU 99857, University of Calicut) on granite rocks.

Description. Total body length 2.0-2.3 mm, width 1.2-1.4 mm. Dorsum metallic black with aeneous reflections (Fig. 45). All sternites dark brown to piceous, legs brown, tarsi darker. Basal 5-7 antennomeres dark brown, rest black. Labrum piceous, rest of mouth parts brown.

In lateral view, frons distinctly higher than vertex; vertex and frons separately appear convex as their intersection being notched. Vertex convex, finely punctate (Fig. 49). Antennal callus convex, triangular, broader than long, high along middle; separated from each other by short midfrontal sulcus, midfrontal longitudinal depression absent. Suprafrontal sulcus distinct. Frontal ridge with small punctures besides a few large, shallow punctures; anterofrontal ridge with vertical carina medially (vertical carina poorly developed in some specimens). Maxillary palpus with preapical palpomere slightly longer than apical. Third antennomere slightly longer than second; fourth shorter than third; fifth and sixth each apparently shorter than preceding one; seventh distinctly wider and longer than sixth; eighth to ninth subequal, wider than seventh, slightly longer than seventh; tenth about as wide as long or longer than wide, subequal to ninth or longer; eleventh two times as long as tenth.

Pronotum slightly narrower anteriorly than posteriorly, lateral margin curved (Fig. 46). Anterolateral callosity not forming denticle at pore. Disc shiny, covered with a mixture of small and moderate sized punctures, 

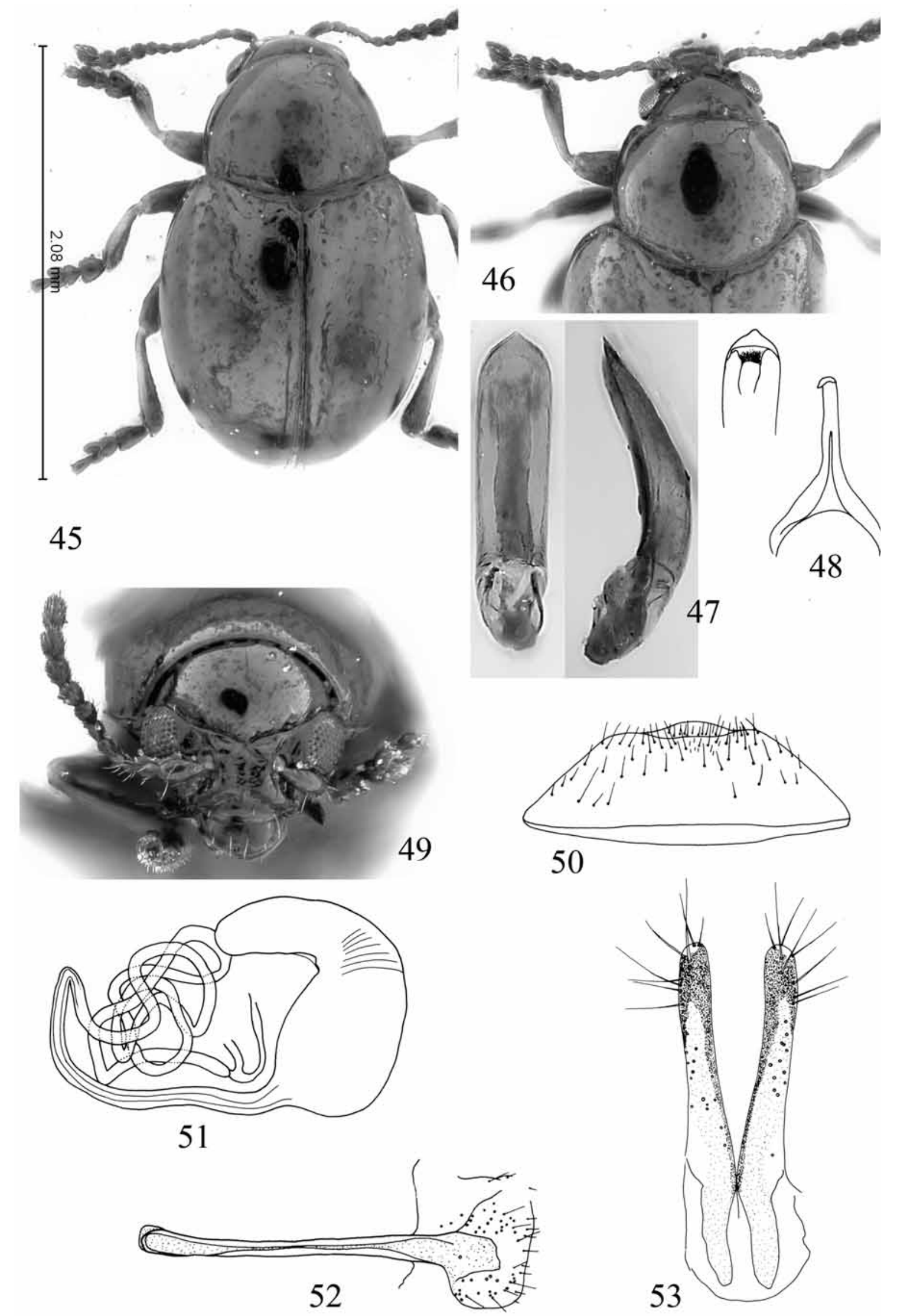

FIGURES 45-53. Phaelota saluki. 45 - dorsal habitus, 46 - pronotum, 47 - median lobe of aedeagus in ventral, lateral, and dorsal views, 48 - tegmen, 49 - head, 50 - last abdominal sternite of male, 51 - spermatheca, 52 - tignum, 53 - vaginal palpi. 
punctures stronger posteriorly. Antebasal transverse impression absent except for curved longitudinal impressions laterally. Scutellum triangular, broader than long with broad apex, with a few extremely minute punctures. Elytron with flat humerus, without depression posteriorly or mesally, maximum width anterior to middle. Disc shiny, punctures small, indistinct posteriorly, width of interstices 6-12 times diameter of a puncture in middle of elytron. Epipleuron oblique, slightly short of reaching apex. Hind wings rudimentary. Prosternum coarsely punctate with a longitudinal ridge along middle (ridge indistinct in some specimens). Metasternum slightly shorter than prosternum.

Posterior margin of last abdominal sternite in male weakly bisinuate with a short lobe (Fig. 50). Median lobe of aedeagus curved in lateral view (Fig. 47). Ventral side convex, semi-transparent, nearly parallel sided, depressed apically. Dorsal opening partially covered by three laminae. Arm of tegmen shorter than stem (Fig. 48). Receptacle of spermatheca a little longer than pump, internal as well as external sides convex, a little longer than wide, oval in shape; pump with horizontal part longer than vertical; duct at least three times as long as combined length of receptacle and pump, coiled (Fig. 51). Vaginal palpus with posterior sclerotization longer than anterior; membranous part in middle shorter than anterior sclerotization; minimum width at distal $1 / 4$, slightly widened posterior to that (Fig. 53). Tignum anteriorly slightly widened and slightly curved, posterior sclerotization widened (Fig. 52).

Sexual dimorphism. First metatarsomere ventrally with short capitate setae in male and with long pointed setae in female. Metafemur not sexually dimorphic.

Type material. Holotype $\overbrace{}^{3}$. Labels: 1) South India Western Ghats Tamil Nadu, Doddabetta, 22.VI.2004 2600m, N11 23'59"E7644'06" Prathapan K. D. Coll. 2) Holotype Phaelota saluki sp. nov. des. D. Prathapan, A. Konstantinov, 2007 (USNM).

Paratypes. $10 \AA, 11 q$ same data as holotype. 1 q same locality, date 24. XI. 2003 leg. Konstantinov, Prathapan, Saluk. (9 USNM, 4 BMNH, 2 NHMB, 2 NPC, 2 UASB, 3 PKDC).

Etymology. This species is named after our companion Sergei Saluk who sifted out the first specimen. The name is a noun.

Remarks. This species has been placed in Phaelota with considerable trepidation. The pronotum is $1.6-$ 1.8 times wider than long in all other species, but only 1.3 times wider than long in $P$. saluki, and the anterior callosity forms a distinct denticle at the pore in the other species, but not in P. saluki. The metafemur is greatly swollen with a longitudinal ridge which is serrulate in the male in all other members of the genus, it is less incrassate and lacks the typical sexual dimorphism in this species. Unlike in other species of the genus, the spermathecal duct is unusually long and coiled in $P$. saluki ( $P$. jacobyi has an extremely long spermathecal duct, but not coiled). Its placement in Phaelota is justified by the structure of the head, indications of the antebasal transverse impression by the lateral longitudinal impressions on the pronotum, serially arranged elytral punctures, broad epipleuron reaching near apex, general structure of legs, and vaginal palpus.

P. saluki can be differentiated easily from other species of the genus by its metallic black dorsum with aeneous reflections besides the above unique features.

\section{Phaelota schereri, new species}

(Figs 54-58)

Distribution. Sri Lanka.

Host plants. Unknown.

Description. Total body length $3.5 \mathrm{~mm}$, width $2.5 \mathrm{~mm}$. Body light brown with elytron much lighter in color (Fig. 54).

In lateral view, vertex and frons form convex line, their intersection being concave and proximal end of frons higher than vertex. Vertex densely covered with varying in size, but mostly small punctures (Fig. 56). 

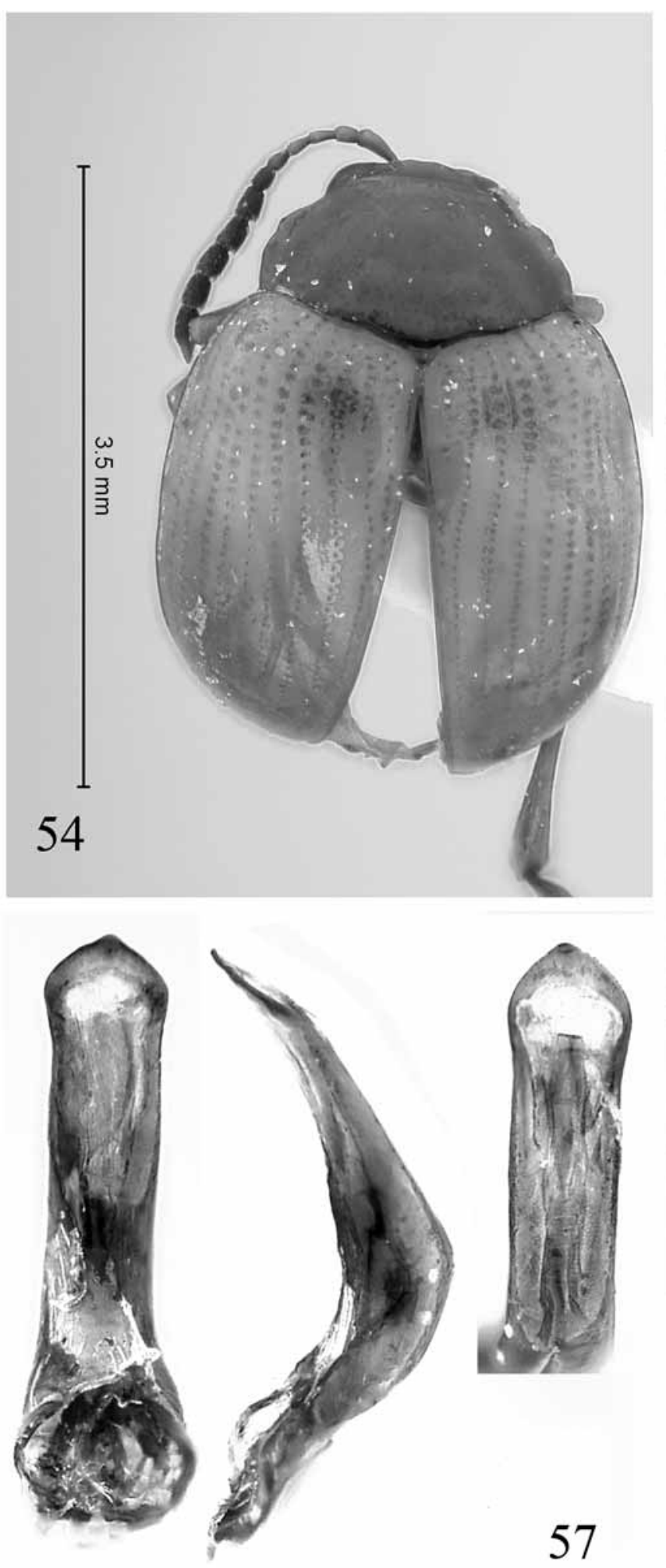
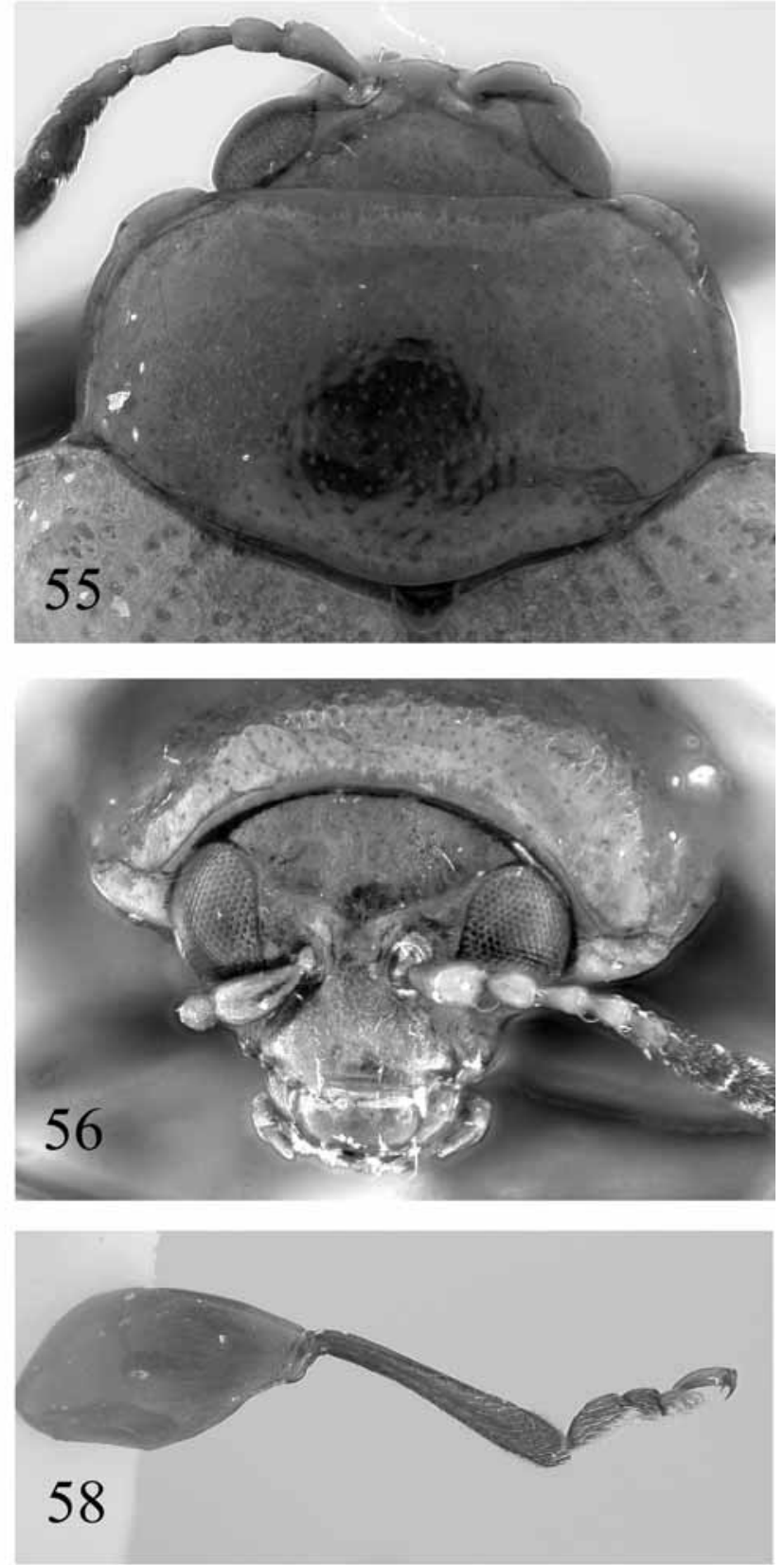

FIGURES 54-58. Phaelota schereri. 54 - dorsal habitus,; 55 - pronotum, 56 - head, 57 - median lobe of aedeagus in ventral, lateral, and dorsal views, 58 - metafemur.

Antennal callus slightly raised, oblique, shorter than wide, as low near supracallinal sulcus as near supraantennal sulcus, separated from each other by relatively wide midfrontal depression (Fig. 56). Suprafrontal sulcus poorly developed medially, absent laterally, midfrontal sulcus absent. Frontal ridge impunctate. Anterofrontal ridge with vertical carina medially. Maxillary palpus with preapical palpomere 0.8 times length 
of apical palpomere. Third antennomere nearly as long as second. Tenth antennomere 0.7 times as wide as long.

Lateral margin of pronotum slightly convex (Fig. 55), anterolateral callosity forms acute denticle at pore. Disc shiny, punctation coarse, much stronger than that on vertex and as coarse as that of elytron. Antebasal transverse impression present. Poorly defined longitudinal impression situated along entire length of lateral margin. One more sharp, relatively long impression located at basal part of pronotum. Scutellum shiny, impunctate, triangular, wider than long, apex narrowly rounded. Elytron with well developed humeral callus (Fig. 54), without depression posteriorly, maximum width at proximal 1/3. Striae not depressed. Interstices flat with punctures much smaller than those of striae. Width of interstices subequal to 4-7 times diameter of a puncture. Epipleuron oblique, not reaching apex. Metasternum about two times as long as prosternum. Metafemur with obtuse denticle on posterior edge (Fig. 58). Metatibia straight in lateral view, curved from dorsal view, proximal 1/3 dorsally convex, rest of surface nearly flat. Claw longer than metatibial spine.

Median lobe of aedeagus strongly curved in lateral view (Fig. 57), with side slightly constricted before apex in lateral view. Ventral side convex with membranous window in apical half, without pair of longitudinal depressions. Dorsal opening partially covered by lamina sclerotized along middle (Fig. 57).

Female unknown.

Type material. Holotype đ̊. Labels: 1) Ceylon: Kan, Dist., Udawattakelle, 25-30 Oct. 1966, J.F.G. Clarke Thelma M. Clarke; 2) Phaelota schereri sp. nov. des. Prathapan and Konstantinov, 2008 (USNM).

Etymology. This species is named after Gerhard Scherer for his contribution to the study of flea beetles. The name is a noun.

Remarks. In the key, $P$. schereri is in the same couplet with $P$. ogloblini from which it can be easily separated by its larger size, the presence of the longitudinal impression along the lateral side of the pronotum (in $P$. ogloblini pronotum lacks such an impression), the metafemur with an obtuse denticle on its posterior edge (in P. ogloblini the denticle is sharp), and the median lobe of the aedeagus being slightly constricted before the apex in ventral view (in $P$. ogloblini it is straight).

\section{Phaelota variabilis (Jacoby), status restored}

(Figs 70-75)

Thrylaea variabilis Jacoby, 1887: 99 (Sri Lanka, lectotype, designated here, examined, BMNH). Maulik, 1926: 308-309; Ogloblin, 1930: 98 (synonymy); Scherer, 1969: 234.

Distribution. Sri Lanka.

Host plants. Unknown.

Description. Total body length $2.3 \mathrm{~mm}$, width $1.7 \mathrm{~mm}$. Head, pronotum, legs, all ventrites, basal six antennomeres and scutellum brown (Figs 70-73). Elytron dark brown with lighter apex, epipleuron, humerus and sutural area. Distal five antennomeres black, last with lighter apex.

Frons and vertex form slightly convex line in lateral view, frons being more convex than vertex. Vertex moderately flat, sparsely punctate (Fig. 73). Antennal callus moderately raised, nearly transverse, high near supracallinal sulcus than near supraantennal sulcus, separated from each other by short midfrontal depression hardly entering into interantennal space. Midfrontal sulcus weak. Suprafrontal sulcus absent. Frontal ridge sparsely minutely punctate. Anterofrontal ridge without vertical carina medially. Maxillary palpus with preapical palpomere slightly longer than half of apical.

Second and third antennomeres subequal; fourth to sixth each progressively but slightly decrease in length; seventh about two times thicker and longer than sixth; eighth and ninth each slightly longer and thicker than seventh; tenth slightly shorter than ninth but as thick as ninth; eleventh slightly less than two times length of tenth. Width of tenth antennomere more than half of its length (Fig. 75). 

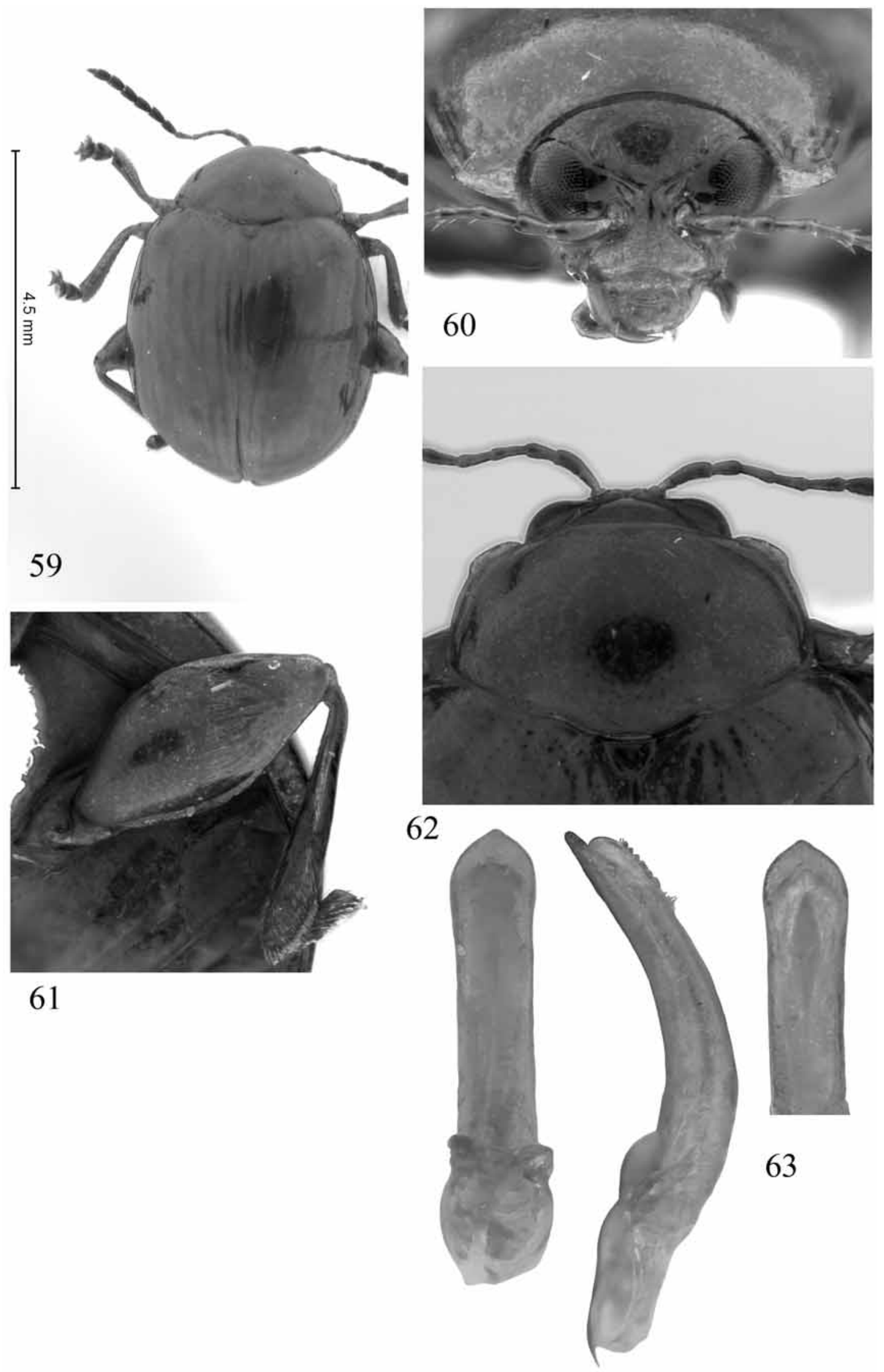

FIGURES 59-63. Phaelota sindhoori. 59 - dorsal habitus, 60 - head, 61 - metafemur, 62 - pronotum, 63 - median lobe of aedeagus in ventral, lateral, and dorsal views. 

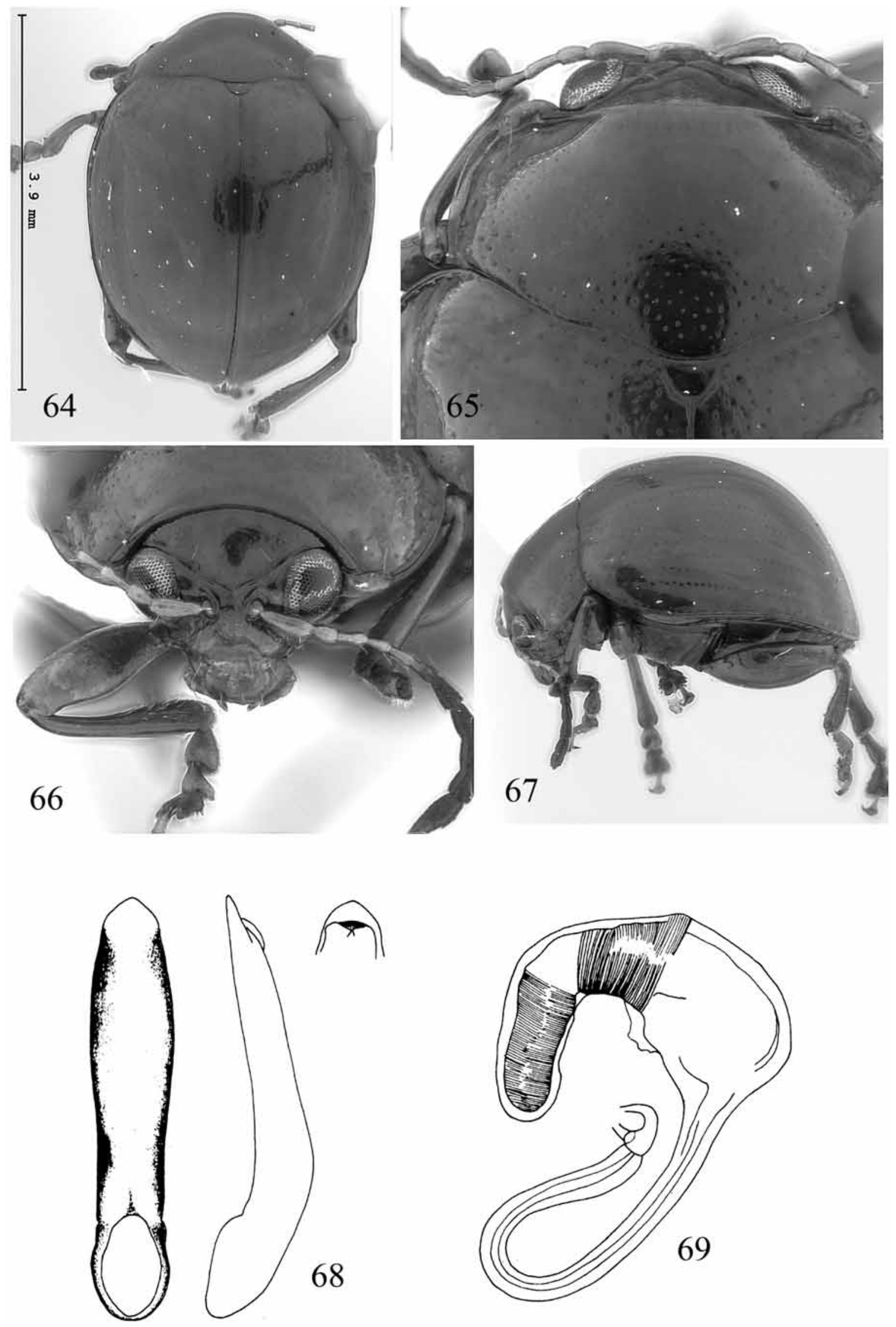

FIGURES 64-69. Phaelota vaishakha. 64 - dorsal habitus, 65 - pronotum, 66 - head, 67 - lateral habitus, 68 - median lobe of aedeagus in ventral, lateral, and dorsal views, 69 - spermatheca. 
Pronotum slightly narrower anteriorly than posteriorly. Lateral margin weakly curved (Fig. 71). Anterolateral callosity forming obtuse denticle at pore. Disc shiny, punctation fine with scattered moderate sized punctures besides a few strong punctures in antebasal transverse impression. Antebasal transverse impression distinct on either ends, indistinct in middle. Scutellum shiny, finely granulate, wider than long, apex narrowly rounded. Elytron with well developed humeral callus, with barely perceptible depression posteriorly, maximum width at proximal $1 / 3$, interstices moderately convex with minute punctures. Width of interstices subequal to 2-5 times diameter of a puncture. Epipleuron subhorizontal, not reaching apex. Metasternum about two times as long as prosternum.

Metatibia straight in lateral view, slightly curved from dorsal view, dorsally convex in proximal 2/3, rest of surface flat (Fig. 72). Metatibial spur much shorter than claw. Proximal margin of last abdominal sternite with setose emargination in middle.

Median lobe of aedeagus gently curved in lateral view (Fig. 74). Ventral side convex, slightly narrowed in middle, apex gently depressed and bent ventrally with a pair of oblong abruptly ending depressions preapically (Fig. 74); dorsal opening partially covered by lamina sclerotized along middle.

Female unknown.

Type material examined. Lectotype ${ }^{1}$. Labels: 1) Ceylon Lewis 2) $1^{\text {st }}$ Jacoby Coll. 3) Thrylaea variabilis Jac 4) Type 19040; 5) Lectotype Phaelota variabilis (Jacoby) des. Prathapan and Konsantinov, 2008 (BMNH).

Remarks. Ogloblin (1930) synonymized Phaelota variabilis with P. flavipennis (Motschulsky). Comparison of the syntype of $P$. variabilis with $P$. flavipennis revealed important characters that reliably separate these two species (see the key below) and we therefore recognize $P$. variabilis as valid. In the key this species is in the same couplet with P. flavipennis, from which it can be easily differentiated by the median lobe of the aedeagus with two abruptly ending impressions basally (Fig. 74). In P. flavipennis the impressions end gradually (Fig. 12).

\section{Phaelota viridipennis, new species}

(Figs 76-82)

Distribution. India (Tamil Nadu).

Host plants. The types were collected by sifting moss on tree trunks and rocks.

Description. Total body length $2.3-2.9 \mathrm{~mm}$, width $1.3-1.7 \mathrm{~mm}$. Elytron metallic black with greenish reflections (Fig. 76). Pronotum bright brown. Frons, mouth parts, basal six antennomeres, legs brown. Vertex dark brown to piceous. Scutellum dark brown. All sternites dark brown to piceous. Distal five antennomeres black, apex of last antennomere brownish, sixth antennomere darker than fifth.

In lateral view, frons distinctly higher than vertex; vertex and frons separately appear convex as their intersection being notched. Vertex convex, minutely punctate (Fig. 77). Antennal callus convex, triangular, broader than long, high along middle. Midfrontal longitudinal depression absent, antennal calli connected. Midfrontal sulcus distinct. Suprafrontal sulcus poorly developed. Frontal ridge sparsely minutely punctate. Anterofrontal ridge with vertical carina medially. Maxillary palpus with preapical palpomere slightly shorter than half of apical. Second and third antennomeres subequal, fourth apparently shorter than third; fifth distinctly longer than fourth; sixth subequal to fourth or shorter; seventh distinctly wider, longer than sixth; eighth subequal to seventh in length, wider than seventh; ninth subequal to eighth; tenth slightly wider and longer than ninth, as wide as long; eleventh two times as long as tenth.

Pronotum slightly narrower anteriorly than posteriorly, lateral margin weakly curved (Fig. 80); anterolateral callosity forming blunt obtuse denticle at pore. Disc shiny, covered with a mixture of small and minute 


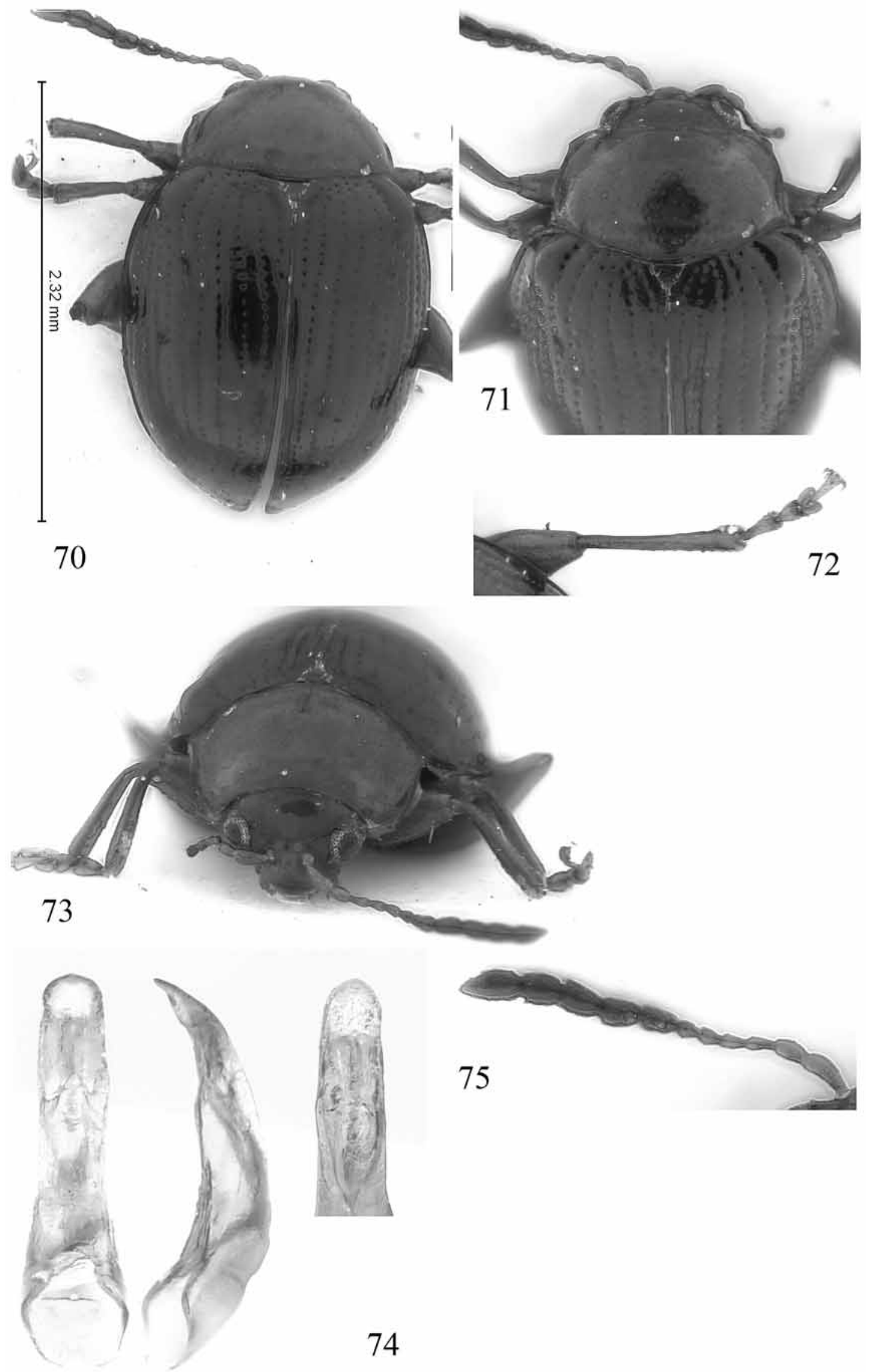

FIGURES 70-75. Phaelota variabilis. 70 - dorsal habitus, 71 - pronotum, 72 - metafemur, 73 - head, 74 - median lobe of aedeagus in ventral, lateral, and dorsal views; 75 - antenna. 

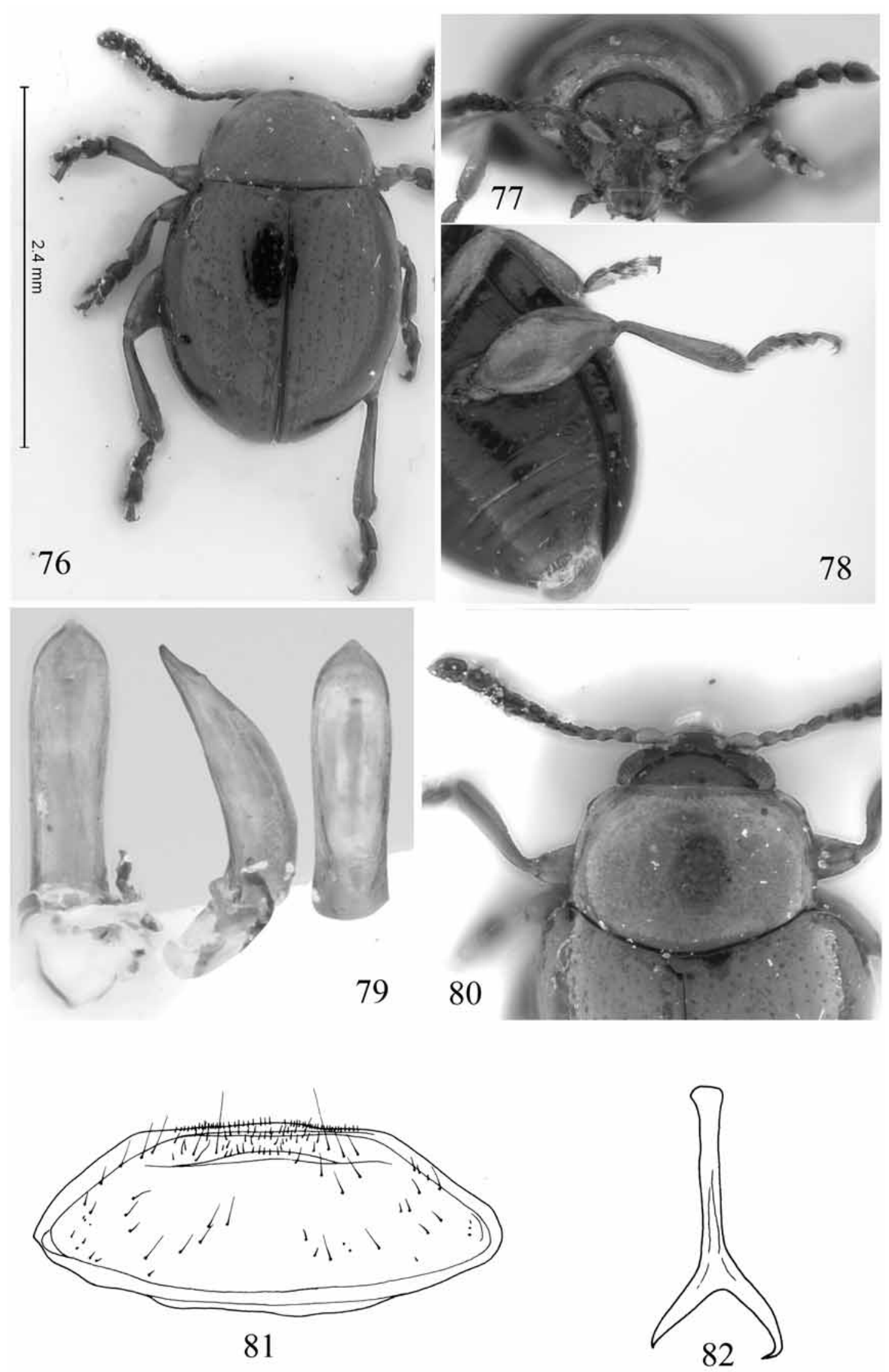

FIGURES 76-82. Phaelota viridipennis. 76 - dorsal habitus, 77 - head, 78 - metafemur, 79 - median lobe of aedeagus in ventral, lateral, and dorsal views, 80 - pronotum, 81 - last abdominal sternite of male, 82 - tegmen. 
punctures, punctures being stronger posteriorly. Curved longitudinal impressions laterally delimiting antebasal transverse impression distinct, antebasal transverse impression not evident in middle. Scutellum semicircular, extremely minutely punctate. Elytron with humerus flat, without depression posteriorly or mesally, maximum width at anterior 1/3. Surface shiny, punctures bold, deep, turning shallow yet distinct posteriorly. Interstices flat, minutely punctured, width of interstices vary from 3-8 times diameter of a puncture in middle of elytron. Epipleuron oblique, slightly short of reaching apex. Metasternum slightly shorter than prosternum. Metatibia nearly straight from lateral and dorsal views; dorsal surface flat in distal $1 / 3$, rest of it convex. Metatibial spine shorter than tarsal claw.

Posterior margin of last abdominal sternite of male neither bisinuate nor with a lobe in middle, weakly convex, with a row of short setae near middle (Fig. 81).

Median lobe of aedeagus curved in lateral view (Fig. 79); in ventral view slightly narrowed before middle, ventral side convex with flat apex; dorsal opening covered by three laminae, middle one sclerotized. Arm of tegmen about half as long as stem (Fig. 82).

Female unknown.

Sexual dimorphism. All first tarsomeres are ventrally flat with short, capitate plumose setae and the metafemora is serrulate. Though no females were examined, it is certain that these are sexually dimorphic characters as in other congeners.

Type material. Holotype $\widehat{~}$. Labels: 1) SOUTH INDIA Western Ghats Tamil Nadu, Nilgiri, env. Ooti Longwood shola 25.XI.2003 1993m, N11²6'16" E76 52' 36", leg.

Konstantinov, Prathapan, Saluk; 2) Holotype Phaelota viridipennis sp. nov. des. D. Prathapan, A. Konstantinov, 2007 (USNM).

Paratypes: 7 the same labels as holotype; 1 same data except the date 21. X. 2003 and the collector Prathapan; 4 S SOUTH INDIA Western Ghats Tamil Nadu, env. Ooti, mt. Doddabetta, 27.XI.2003 2600m, N11 ${ }^{\circ} 3^{\prime} 59^{\prime E}$ E76 $44^{\prime} 06^{\prime \prime}$ moss leg. Konstantinov, Prathapan, Saluk (5 USNM, 2 BMNH, 1 NHMB, 1 NPC, 1 UASB, 2 PKDC)

Etymology. The specific epithet refers to the dark metallic green elytron and is an adjective.

Remarks. Phaelota viridipennis can be easily separated from all other species of Phaelota by its unique coloration: bright brown head and pronotum and aeneous elytron. All 13 individuals studied are males though they were collected at two localities. The sex ratio in this species appears to be strangely skewed towards males.

\section{Key to the species of Phaelota of the Indian subcontinent}

1. Humerus flat, hind wings absent or rudimentary; metathoracic sternite not longer than prothoracic sternite; moss dwelling

Humeral callus well developed, hind wings well developed; metathoracic sternite about two times as long as prothoracic sternite; fern feeding

2 (1). Elytron reddish brown with dark longitudinal stripes; tenth antennomere as wide as half of its length; length 5.0 $\mathrm{mm}$.............................................................................................................. P. semifasciata Jacoby Elytron either metallic or a mixture of black and yellow; tenth antennomere wider than half of its length; length $1.9-2.8 \mathrm{~mm}$

3 (2). Elytron all around and suture piceous enclosing light yellowish area in middle with black macula; ventral side of aedeagus with a longitudinal deep groove not reaching apex (Fig 25); spicule Y-shaped.....

P. maculipennis n. sp.

Elytron metallic black or green; ventral side of aedeagus without deep groove; spicule not Y-shaped ............... 4

4 (3). Dorsum entirely metallic black with aeneous reflections; longitudinal ridge along mesal side of metafemur not serrulate in male. P. saluki n. sp. Elytron greenish black, head and pronotum bright brown; metafemur with longitudinal ridge along mesal side serrulate in male. $P$. viridipennis $\mathbf{n}$. sp. 
5 (1). Elytra with spots or bands, either dark on light background or light on dark background (P. vaishakha) .......... 6

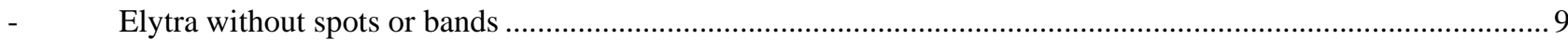

6 (5). Pronotum with large dark spot in the middle ................................................................. P. assamensis n. sp.

- $\quad$ Pronotum entirely light or dark colored, without spot in the middle ........................................................

7(6). Vertex covered with relatively large, distinctly visible punctures

- $\quad$ Vertex covered with tiny, barely perceptible punctures........................................................................ 8

8 (7). Spermathecal duct nearly as long as receptacle, making large loop.

. P. vaishakha Prathapan and Viraktamath (in part) (Figs 64-69)

- $\quad$ Spermathecal duct much shorter than receptacle, making a small loop............................... P. kottigehara n. sp.

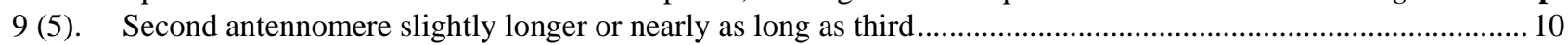

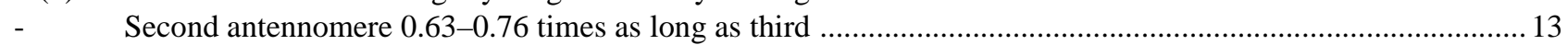

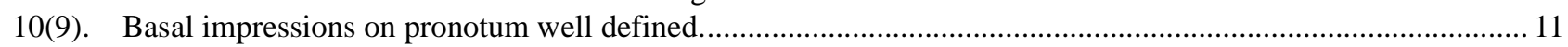

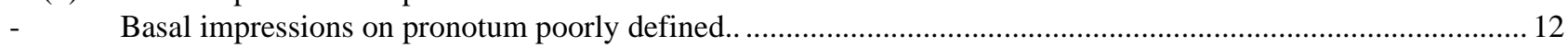

11 (10). Median lobe of aedeagus with apex bent ventrally and lateral impressions ending abruptly (Fig. 74) .................

P. variabilis (Jacoby)

Median lobe of aedeagus with apex bent dorsally and lateral impressions ending gradually towards base (Fig. 12)

P. flavipennis (Motschulsky)

12 (10). Pronotum without poorly defined longitudinal impression along its lateral margin. Metafemur in male with sharp denticle. Median lobe of aedeagus with sides straight (Fig. 44) ..................................... ogloblini n. sp. Pronotum with poorly defined longitudinal impression along its lateral margin. Metafemur in male with obtuse denticle. Median lobe of aedeagus with sides slightly constricted before apex (Fig. 57) ............. P. schereri n. sp.

13 (9). Maximum width of median lobe of aedeagus situated slightly above middle. Spermatheca with a duct as long or longer than receptacle ......................................... vaishakha Prathapan and Viraktamath (in part) (Figs 64-69)

Maximum width of median lobe of aedeagus situated near apex. Spermatheca with a duct shorter than receptacle.

14 (13). Median lobe of aedeagus slightly narrower in middle than basally and apically, uniformly sclerotized in ventral view (Fig. 63). Anterofrontal ridge not vertically carinate medially (Fig. 60); lateral margin of pronotum curved (Fig. 62) ......................................................................... P. sindhoori Prathapan and Viraktamath (Figs 59-63) Median lobe of aedeagus parallel-sided, with membranous part near apex in ventral view (Fig. 34). Anterofrontal ridge vertically carinate medially; lateral margin of pronotum almost straight (Figs 31-33)... P. mauliki n. sp.

\section{Discussion}

Phaelota is an illustrious example for the consequences of loss of flight. The genus is divisible into two distinct species groups based on the ability to fly. Each of these groups exhibit unique features in morphology and ecology, yet have a number of features common to all the species. All the flightless species are distinctly smaller (except $P$. semifasciata which is $5.0 \mathrm{~mm}$ long), live in moss, and inhabit higher elevations above 1470 $\mathrm{m}$, while the alate species are larger in size, feed on ferns, and occur also at lower elevations of about $1000 \mathrm{~m}$. In general, flightless genera are montane and apterism is an adaptation for the windy high mountains. The apterous species, owing to a higher level of specialization and adaptation are restricted in distribution compared to the alate ones.

Loss of flight has a direct bearing on the extent of development of the thorax. Severe reduction of the external and internal structures of the thorax due to loss of flight has been reported in other flea beetles (Konstantinov, 2002; Döberl and Konstantinov, 2003; Konstantinov and Duckett, 2005; Konstantinov and Chamorro-Lacayo, 2006). The metasternum is greatly reduced in length (slightly shorter than prosternum), the humerus is flat and the mesoscutellum is semicircular or has a broadly rounded apex in apterous Phaelota, whereas in the alate species the metasternum is twice as long as the prosternum, the humeral callus is well developed, and the mesoscutellum is distinctly triangular with a narrow apex.

Though the impact of the loss of wings on the morphology is better investigated in flea beetles, a shift in host plant selection due to loss of flight is little known. Ivalia Jacoby is another Oriental genus with alate and apterous species, mostly occurring in high mountain ranges (Duckett et al., 2006; Prathapan, unpublished 
data). But at least in southern India, both species groups in Ivalia are moss dwelling and the selection of host plants is not influenced by loss of flight.

In Ivalia, evidently host plant selection preceded loss of flight. It could be argued that in Phaelota too loss of flight occurred after selection of mosses as host plants. But as no winged moss dwelling Phaelota is known, there is little evidence in support of this contention.

\section{Acknowledgements}

We thank S. Shute (BMNH) for the opportunity to study specimens in her care. Forsstroemia thomsonii was identified by C. N. Manju and K. P. Rajesh of the Calicut University, India. We thank K. D. Ghorpade, Bangalore for organizing a collection trip in south India and S. Saluk for great collecting. We are grateful to J. Prena (Systematic Entomology Laboratory, ARS, USDA, Washington, DC) for advice on formation of specific epithets. We thank M. Gates and A. L. Norrbom (Systematic Entomology Laboratory, ARS, USDA, Washington, DC), and C. Staines (Department of Entomology, Smithsonian Institution, Washington, DC) for reviewing earlier versions of this manuscript and providing valuable suggestions. PKD is grateful to CAV for guidance and support.

\section{Literature cited}

Chen, S.H. (1936) Genera of Oriental Halticinae. Sinensia, 7(6), 625-667.

Döberl, M. \& Konstantinov, A.S. (2003) A new genus of flea beetles from Nepal (Coleoptera: Chrysomelidae). The Coleopterists Bulletin, 57(2), 205-218.

Duckett, C.N., Prathapan K.D. \& Konstantinov, A.S. (2006) Notes on identity, new synonymy and larva of Ivalia Jacoby (Coleoptera: Chrysomelidae) with descriptions of a new species. Zootaxa, 1363, 49-68.

Heikertinger, F. \& Csiki, E. (1940) Pars 166-169. Chrysomelidae. Halticinae. In: Junk, W. and Schenkling, S. (Eds) Coleopterorum Catalogus. Dr W. Junk, Gravenhage, 635 pp.

Jacoby, M. (1887) Descriptions of the Phytophagous Coleoptera of Ceylon, obtained by Mr. George Lewis during the years 1881-1882. Proceedings of the scientific meetings of the Zoological Society of London for the year, 1887, $65-119$.

Konstantinov, A.S. (1998) Revision of the Palearctic species of Aphthona Chevrolat and cladistic classification of the Aphthonini (Coleoptera: Chrysomelidae: Alticinae). Memoirs on Entomology, International, Associated Publishers, Gainesville, 429 pp.

Konstantinov, A.S. (2002) A new genus of flea beetles from the Greater Antilles (Coleoptera: Chrysomelidae). Zootaxa, $124,1-24$.

Konstantinov, A.S. \& Chamorro-Lacayo, M.L. (2006) A new genus of moss-inhabiting flea beetles (Coleoptera: Chrysomelidae) from the Dominican Republic. The Coleopterists Bulletin, 60(4), 275-290.

Konstantinov, A.S. \& Duckett, C.N. (2005) New species of Clavicornaltica Scherer (Coleoptera: Chrysomelidae) from continental Asia. Zootaxa, 1037, 49-64.

Maulik, S. (1926) The Fauna of British India, including Ceylon and Burma. Coleoptera. Chrysomelidae (Chrysomelinae and Halticinae). "Taylor and Francis", London, 442 pp.

Medvedev, L.N. (2006) To the knowledge of Chrysomelidae (Coleoptera) described by V. Motschulsky. Russian Entomological Journal, 15(4), 409-417.

Motschulsky, V. (1866) Essai d'un Catalogue des Insectes de l'ile de Ceylan. Supplement. Bulletin de la Société Impériale des Naturalistes de Moscow, 39, 393-446.

Ogloblin, D.A. (1930) De quelques especes de Halticinae (Col. Chrysomelidae) de la collection de V. Motschulsky. Museo Nacional de Sciences Naturales Madrid, 10, 84-111.

Prathapan, K.D. \& Viraktamath, C.A. (2004) Revision of Phaelota Jacoby (Coleoptera: Chrysomelidae) with descriptions of three new species. Zootaxa, 447, 1-18.

Scherer, G. (1969) Die Alticinae des indischen Subkontinentes (Coleoptera-Chrysomelidae). Pacific Insects Monograph, 22, 1-251.

Seeno, T.N. \& Wilcox, J.A. (1982) Leaf beetle genera (Coleoptera: Chrysomelidae). Entomography, 1, 1-221. 